Tri Vi Dang

Florian Morath

\title{
The Taxation of Bilateral Trade with Endogenous Information
}

\author{
Max Planck Institute for Tax Law and Public Finance \\ Working Paper 2013 - 07
}

November 2013

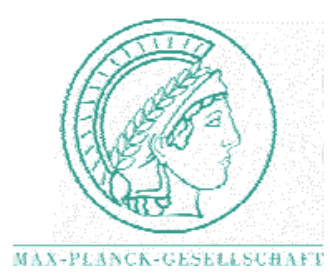

Max Planck Institute for Tax Law and Public Finance

Department of Business and Tax Law

Department of Public Economics

http://www.tax.mpg.de 
Working papers of the Max Planck Institute for Tax Law and Public Finance Research Paper Series serve to disseminate the research results of work in progress prior to publication to encourage the exchange of ideas and academic debate. Inclusion of a paper in the Research Paper Series does not constitute publication and should not limit publication in any other venue. The preprints published by the Max Planck Institute for Tax Law and Public Finance represent the views of the respective author(s) and not of the Institute as a whole. Copyright remains with the author(s).

Max Planck Institute for Tax Law and Public Finance

Marstallplatz 1

D-80539 Munich

Tel: $\quad+498924246-0$

Fax: $\quad+498924246-501$

E-mail: ssrn@tax.mpg.de

http://www.tax.mpg.de 


\title{
The Taxation of Bilateral Trade with Endogenous Information
}

\author{
Tri Vi Dang $^{\mathrm{a}} \quad$ Florian Morath $^{\mathrm{b}}$
}

November 2013

\begin{abstract}
This paper analyzes the effects of taxation on trade in a decentralized market. We show that a tax on profits and a transaction tax have opposite implications for information acquisition and trade in the canonical take-it-and-leave-it offer bargaining model. A (marginal) increase of a transaction tax can lead to more information production and lower the probability of efficient trade. In contrast, a (marginal) increase of a profit tax can reduce the incentive to produce information and increase the probability of efficient trade. The taxation of profits can be efficiency enhancing when information is endogenous, while it has no effect when private information is exogenous.
\end{abstract}

Keywords: Bargaining; information acquisition; taxation; financial transaction tax; funding markets

JEL Codes: C78; D82; D83; G18; H20

\footnotetext{
${ }^{a}$ Columbia University, e-mail: td2332@columbia.edu.

${ }^{\mathrm{b}}$ Max Planck Institute for Tax Law and Public Finance, e-mail: florian.morath@tax.mpg.de.
} 


\section{INTRODUCTION}

In this paper we analyze the effects of taxation on trade in a decentralized market where agents are uncertain about the value of the asset but can acquire information about the asset's payoff. We focus on two standard tax instruments (a tax on profits or capital gains and a sales tax) and show that, by changing the incentives to acquire information, taxation influences the endogenous problem of asymmetric information and hence the probability of trade.

The question of how taxation affects information acquisition and bilateral trade is an interesting and important question. The bargaining literature is large but taxation in bargaining and models of optimal contracting with endogenous information is an unexplored topic. While it is a standard result in the literature that asymmetric information typically causes the equilibrium to be inefficient, asymmetric information is often the outcome of individual choices to invest in information acquisition. In such situations, taxation does not only affect the decision of whether to trade but also information acquisition; taking into account that information asymmetries arise endogenously can lead to different conclusions on the effects of taxation than when private information is exogenous.

This topic is also relevant since bargaining, information acquisition and taxation of capital gains are present in many bilateral financial transactions such as bargaining and trade in funding markets. The main purpose of trade in decentralized funding markets is short term liquidity management (Bank of Canada 2012, IMF 2008). The players in funding markets are banks, insurance companies, pension funds, money market funds, hedge funds and cash managers of corporations. These players have large cash balances and typically trade hundreds of millions or even billions of dollars of short term debt instruments (or wholesale funds) such as repos, interbank deposits, government bonds, asset backed commercial papers, Agency and non-Agency mortgage backed securities so as to manage their short term liquidity needs.

The breakdown of some of these markets in the wholesale banking system was a key problem of the recent financial crisis (Gorton and Metrick 2011, Deutsche Bank 2012, McKinsey 2013). The change of macroeconomic fundamentals (or a shift of the asset's payoff distribution) can make an asset that was information insensitive (in the terminology of Dang, Gorton, and Holmstrom 2012a,b) to become information sensitive and thus increases the incentive of sophisticated agents to produce information. A notable example which attracted much public attention was the 
speculation against mortgage backed securities by the Paulson Hedge Fund. ${ }^{1}$ Less sophisticated market participants became concerned about endogenous lemons problems, which some market participants and regulators considered as one of the reasons for the breakdown of asset backed securities markets during the financial crisis.

The financial crisis has drawn attention to a taxation of the financial sector. In February 2013, The European Commission $(2013$, p.2) proposes to implement a financial transaction tax and states: "The main objectives of this proposal were: [...] creating appropriate disincentives for transactions that do not enhance the efficiency of financial markets thereby complementing regulatory measures to avoid future crises." According to a Bloomberg article, the European Union is trying to remedy what it sees as a patchwork of levies and rein in speculative trading. ${ }^{2}$ Some market participants raise concerns about a transaction tax. In particular, lobby groups of short term debt funding markets, such as the European Repo Council, part of the International Capital Market Association, recommended lobbying for repos and securities lending to be exempt from the tax, along with primary dealers and market makers operating in bond markets, and argued that "without exemptions the 'seismic change' would lead to short-term repos shrinking by two-thirds in Europe, harming lending to the economy."3

A theoretical analysis of the taxation of financial transactions in decentralized markets can provide important insights for the taxation and regulation of funding markets. In this paper we discuss three questions. How does taxation affect an agent's incentive to produce information and to speculate in a decentralized market? What is the effect of taxation on the equilibrium probability of trade? How does a profit tax differ from a sales tax in terms of its effects on information production and the probability of trade?

To answer these questions about the effect of taxation in bilateral trade with endogenous information, we like to think of the analysis of taxation in the canonical take-it-or-leave-it-offer bargaining model as a very stylized model that captures trade of asset backed securities, an

\footnotetext{
${ }^{1}$ The valuation of MBS requires special expertise and data intensive simulation models. More generally, hedge funds produce a large amount of information as inputs for their trading system. Information production is a key activity in security markets in which assets are information sensitive.

${ }^{2}$ See Bloomberg (5/22/2013), EU Aides Say Transaction Tax Design Hurts Sovereign Debt, Rebecca Christie.

${ }^{3}$ See Reuters (4/8/2013), Markets step up fight against EU transaction tax, Huw Jones.
} 
important part of funding markets. ${ }^{4}$ The structure that we consider, however, is more general in that it applies to many types of bilateral trade such as buying and selling real estate properties, trade of financial assets in over-the-counter markets, mergers and acquisitions or inter-firm trade. Uncertainty and information acquisition as well as standard types of taxation play a role in most of these examples, and a positive and systematic analysis of taxation is both theoretically interesting and relevant when thinking about the behavioral reaction to taxation in decentralized markets.

In our main model, we assume that some agents are sophisticated and can produce information while others are not (or have high cost of information acquisition). More specifically, we consider the case where an uninformed proposer (without private information) makes an offer to a responder who can acquire information before deciding whether to trade. While this assumption is also reflected in funding markets where some investors (e.g., hedge funds) are more capable to produce information than other investors (e.g., regional banks), the main reason for analyzing the case where an uninformed agent makes an offer is tractability. We discuss alternative information acquisition assumptions in section $6 .^{5}$

The main result of the paper is that a tax on profits and a sales (transaction) tax have opposite implications for endogenous information acquisition and trade. A (marginal) increase of a profit tax or capital gains tax can reduce the incentive to produce information and increase the probability of efficient trade. In contrast, a (marginal) increase of a sales tax can lead to more information production and lower the probability of efficient trade. Also, we show that taxation can have a direct effect on the probability of trade if, in equilibrium, there is information production, as well as an indirect effect by affecting the likelihood of information production.

These results are derived in three steps. First, we consider the responder's incentives to acquire information at a given price, and we analyze how taxation affects the incentives for information acquisition. Then, we solve for the equilibrium price setting of the proposer. Finally, we show

\footnotetext{
${ }^{4}$ Our setting is based on Dang, Gorton and Holmstrom (2012a) who analyze a model of optimal security design and sequential trade that captures some important features of trade in funding markets. Since trade in funding markets is of bilateral nature, the workhorse models (Grossman and Stiglitz 1981; Kyle 1985, 1989) in the market microstructure literature on stock trading are less appropriate for studying funding markets.

${ }^{5}$ If a sophisticated investor makes an offer, then this gives rise to an endogenous signaling game where the proposer can produce information and thus be informed or uninformed. If both investors can produce information, then the equilibrium analysis becomes even more complex.
} 
how taxation affects the equilibrium price chosen by the proposer (taking into account the responder's decision on information acquisition) and hence the probability of trade.

We highlight the intuition behind these results for the case where an uninformed seller (e.g., a regional bank) proposes a price to sell an indivisible asset to a buyer (e.g., a hedge fund) who can produce information and then decides whether to buy at the proposed price. In terms of taxation, we consider a tax on the buyer's positive profits (where profit is defined as realized payoff of the asset minus price paid) and a sales tax on the price of the asset.

First of all, while the seller obviously prefers a high price, higher prices increase the buyer's incentives to acquire information, in which case he buys the asset only for favorable signals (or in high payoff states). Therefore, the seller can either charge a low price $p_{I}$, which just prevents the buyer from acquiring information, or he can charge a high price $p_{I I}$, accepting that the buyer will acquire information and only trade for favorable signals. ${ }^{6}$ Compared to buying the asset without information acquisition, the buyer gains from acquiring information only in case he receives an unfavorable signal (low payoff states), for which he does not buy the asset. Therefore, the buyer's incentive to acquire information corresponds to avoiding the loss in case the true payoff of the asset is low. In such a case the value of information is not affected by a tax on positive profits.

On the other hand, profit taxation reduces the buyer's gains from trade if he acquires information. Therefore, when trading with an informed buyer, the seller may have to lower the price $p_{I I}$ in order to make the buyer participate. But lower prices lead to more trade (since an informed buyer trades with higher probability); this is what we call the direct effect of profit taxation on the equilibrium probability of trade.

A second (indirect) effect of profit taxation works through the seller's choice between the prices $p_{I}$ and $p_{I I}$ : Profit taxation does not affect the buyer's incentives to acquire information and hence the price $p_{I}$ (which just prevents information acquisition), but it may reduce the price $p_{I I}$ which must guarantee that an informed buyer's expected gains from trade are sufficient to cover the cost of information. This makes it relatively more attractive for the seller to charge the price $p_{I}$ at which the buyer trades without information acquisition. In other words, profit taxation enlarges the range of cost of information for which there is no information acquisition in equilibrium but trade with probability one.

\footnotetext{
${ }^{6} \mathrm{We}$ assume that the seller is willing to trade with an informed buyer, e.g. because he needs to sell and raise cash.
} 
For the sales tax, we also obtain a direct and an indirect effect, but here both effects are exactly the opposite. First, sales taxes may lead to a higher (tax-inclusive) price in the equilibrium with information acquisition; we show that it is optimal for the seller to shift part of the tax increase to the buyer. But a higher (tax-inclusive) price reduces the equilibrium probability of trade. Second, since the sales tax increases the (tax-inclusive) price that the buyer has to pay, it also strengthens the buyer's incentives to acquire information. Hence, if the seller wants to avoid information acquisition, he has to lower the net-of-tax price when the sales tax is increased. Overall, this makes it relatively less attractive for the seller to charge the price for which there is no information acquisition. Therefore, sales taxes enlarge the range of information cost for which there is information acquisition in equilibrium and trade with probability less than one.

To summarize, sales taxes make trade less attractive and make it, therefore, less attractive to choose a price that prevents information acquisition and ensures trade with higher probability. The opposite is true for a profit tax, which makes preventing information acquisition relatively more attractive and leads to more trade. Note that, qualitatively, the effects of taxation do not depend on whether the buyer or the seller is the responder and can acquire information, even if the agents' incentives to acquire information are different: A buyer decides to acquire information in order to avoid buying the asset in low payoff states, while the seller will acquire information in order to be able to keep the asset in high payoff states. Still we show that the same effects of profit taxes and sales taxes hold in the case where the seller is the responder.

The remainder of the paper is organized as follows. The next section relates the paper to the literature. Section 3 introduces the model. Section 4 provides an equilibrium analysis. Section 5 analyzes the effects of taxation on equilibrium information acquisition and pricing. Section 6 discusses the main assumptions of the paper, and Section 7 concludes. Some of the proofs are given in the Appendix.

\section{RELATED LITERATURE}

In many situations agents can acquire information when they bargain, contract, and trade with each other. A key insight of this strand of the microeconomic literature discussed below is that, when agents have private information, equilibrium outcomes are typically not efficient. In many bilateral transactions in secondary markets, however, rather than there being ex ante asymmetry 
in the information that agents possess, there is asymmetry in the agents' cost or ability to acquire information. There is a relatively small number of papers that analyze information acquisition in bargaining and optimal contracting. These papers show that when information is endogenous, the equilibrium outcome can be very different from the equilibrium outcome under asymmetric information.

Crémer and Khalil (1992) analyze strategic information acquisition in bilateral contracting where the agent can acquire information about his production cost but where, as in our model, information has no social value. They show that the principal will always offer a contract which avoids information acquisition of the agent. Crémer, Khalil and Rochet (1998) analyze socially wasteful information acquisition of the agent that takes place before the contract is offered. Both papers focus on information about a private value. Dang (2008) considers a bargaining model with common values where both the proposer and the responder can acquire information and shows that the mere possibility of information acquisition can cause trade to break down. ${ }^{7}$

In Dang, Gorton and Holmstrom (2012a,b), a proposer designs a security that uses an asset as a collateral and trades the security with a responder who can acquire information. Depending on the identity of the proposer, equilibrium outcomes are different. If the buyer makes an offer to buy a security, then there is never information production by the seller in equilibrium even if the information cost is vanishingly small. If the seller makes the offer, the buyer may acquire information in equilibrium. In order to analyze the effects of taxation on the incentives to acquire information, we consider a simplified contracting setting where the asset is indivisible, neglecting the question of optimal security design. This implies that there will be wasteful information production in equilibrium if the cost of information is small.

The main focus of our paper is to analyze taxation in a contracting setting which captures trade in funding markets. The literature on behavioral effects of taxation is large and multi facet. But to our knowledge there is very little work that analyzes the impact of taxation on bargaining, bilateral trading and optimal contracting. One reason for this might be that (profit) taxation does not alter equilibrium outcomes when private information is exogenous, which is a common assumption in the bargaining and contracting literature. In particular, the effect of taxation on information acquisition in contracting problems seems to have not yet been explored. While

\footnotetext{
${ }^{7}$ There is also a literature on information acquisition in auctions; recent work includes Persico (2000), HernandoVeciana (2009), and Morath and Münster (2013).
} 
taxation does not only affect incentives to acquire information, it also changes the equilibrium price and hence the parties' gains from trade.

The literature on tax incidence has extensively analyzed the conditions that determine the distribution of the burden of taxation among market participants, but this literature typically focuses on complete information (for a survey see Fullerton and Metcalf 2002). Questions of tax incidence with asymmetric information have been analyzed in competitive markets (Cheung 1998, Jensen and Schjelderup 2011) and for monopoly pricing (Goerke 2011, Kotsogiannis and Serfes 2013), mainly comparing ad valorem taxes to per unit taxes. ${ }^{8}$ In our paper, the case where the seller makes the offer and where the cost of information is close to zero is similar to a simple model of monopoly pricing with incomplete information. For higher cost of information, however, the tax incidence effects are also affected by the incentive constraints for information production.

Our paper is also related to the literature on taxation and risk-taking; for seminal contributions see Domar and Musgrave (1944) and Stiglitz (1967), and see Sandmo (1985) for a survey. Since profit taxation reduces the variance of the (after-tax) payoff of the asset, its effect on incentives for information production for a given price could be interpreted as similar to a reduction in risk. In our model, however, the crucial aspect of the effect on the equilibrium price is more subtle. In particular in the case where the seller makes the offer, profit taxation does not directly change the incentives for information production but can nevertheless have an effect on the equilibrium outcome. ${ }^{9}$

Finally, there is a growing literature on taxation of the financial sector and its impact on financial stability. A focus has been on investment decisions and portfolio choice as well as liquidity risk. Financial transaction taxes as a way to reduce speculative investments are discussed in Stiglitz (1989) and Summers and Summers (1989). Recent contributions include Acharya, Pedersen, Philippon, and Richardson (2010) on corrective taxation if there is systemic risk, Keen (2011) on taxation and bank borrowing, and Bierbrauer (2012) who contrasts short-term and long-term effects of a transaction tax in a financial market model. Shackelford, Shaviro, and Slemrod

\footnotetext{
${ }^{8}$ For a second-price auction, Ginsburgh, Legros, and Sahuguet (2010) analyze the incidence effects of commissions, which can also be interpreted as a sales tax.

${ }^{9}$ Effects of taxation in the presence of (exogenous) asymmetric information have also been studied in the context of income and commodity taxation and moral hazard (e.g., Arnott and Stiglitz 1986, Kaplow 1992, Banerjee and Besley 1990) and signaling (e.g., Ireland 1994, Anderson 1996).
} 
(2010) and Matheson (2011) provide an overview of the debate on different forms of taxation as well as empirical evidence. These papers analyze a financial model of the type of centralized stock trading. In contrast, our paper discusses taxation in a bilateral trade model of the type of decentralized funding markets. Our paper hints at an aspect that has not been emphasized in this discussion: Transaction taxes have an additional effect on trade by influencing the problem of endogenous informational asymmetries.

\section{THE MODEL}

We consider a game with two agents: a seller $S$ and a buyer $B$. The seller can sell an indivisible asset with uncertain payoff $x$ at a price $p$ to the buyer. Ex ante the information is symmetric; it is common knowledge that the payoff $x$ is distributed according to the distribution function $F$ on the interval $\left[x_{L}, x_{H}\right]$ where $0 \leq x_{L}<x_{H} . F$ is assumed to be continuous and differentiable on $\left[x_{L}, x_{H}\right]$.

As will be described below, there will be the possibility to acquire information at a cost $\gamma \geq 0$. The ex post utility of agent $i=S, B$ is given by

$$
U_{i}=u_{i}(x, p, q)-\gamma \cdot 1_{\text {info }}, i=S, B,
$$

where $q \in\{0,1\}$ indicates whether there is trade ( $q=1$ if the asset is traded and $q=0$ otherwise) and the indicator variable $1_{\text {info }}$ indicates whether agent $i$ has acquired information (at cost $\gamma$ ). Specifically, we consider the following objective functions:

$$
u_{S}(x, p, q)=\left\{\begin{array}{c}
p-T_{S}\left(p, p_{0}\right) \quad \text { if trade }(q=1) \\
v_{S}(x)-T_{S}\left(x, p_{0}\right) \quad \text { if notrade }(q=0)
\end{array}\right.
$$

and

$$
u_{B}(x, p, q)=\left\{\begin{array}{cc}
v_{B}(x)-(p+\kappa)-T_{B}(x, p+\kappa) & \text { if trade }(q=1) \\
0 & \text { if notrade }(q=0)
\end{array} .\right.
$$

Here, $v_{i}(x)$ is agent $i$ 's valuation of the asset, which is assumed to be continuous and strictly increasing in the asset's payoff $x$. Moreover, $\kappa \geq 0$ is a per unit sales tax to be paid by the buyer. Hence, $\kappa$ increases the tax-inclusive price from $p$ to $p+\kappa$. Finally,

$$
T_{i}(y, z)=\tau \max \{y-z, 0\}
$$


represents a tax payment on positive monetary profit $y$ net of some amount $z \geq 0$, which is deductible for tax purposes. More specifically, agent $i$ makes a positive profit if the realized payoff of the asset is larger than the price paid for the asset; in this case, these positive profits are taxed at rate $\tau \in[0,1)$. For the buyer, a positive profit occurs if he buys the asset and the payoff of the asset is larger than the price $p$. The seller's profit may be subject to taxation either if he does not sell the asset and realizes a payoff $x$ that is larger than some price $p_{0}$ that he initially paid for the asset (the 'book value') or if he sells the asset and receives a price $p$ that is larger than the 'book value' $p_{0}$. This 'book value' $p_{0}$ represents a cost that may be deductible for tax purposes and we assume that $0 \leq p_{0}<x_{H}$.

Given $u_{S}(x, p, q)$ and $u_{B}(x, p, q)$, the outside options of seller and buyer are

$$
\bar{u}_{S}:=E_{x}\left[u_{S}(x, p, 0)\right]=E_{x}\left[v_{S}(x)\right]-E_{x}\left[\tau \max \left\{x-p_{0}, 0\right\}\right]
$$

and

$$
\bar{u}_{B}:=E_{x}\left[u_{B}(x, p, 0)\right]=0 .
$$

We make the following assumption:

$$
v_{S}(x)<v_{B}(x) \text { for all } x \in\left(x_{L}, x_{H}\right] \text {. }
$$

This assumption implies that trade is efficient since the buyer derives a higher value from holding the asset than the seller. ${ }^{10}$

We analyze a simple bargaining game where one of the agents - the proposer $P$ - offers a price; the other agent - the responder $R$ - can acquire information (at cost $\gamma$ ) to learn about the true realization of $x$ and then decides whether to trade. We assume that

$$
v_{R}(x)=x, R \in\{S, B\},
$$

and we only consider a tax on the responder's monetary profit which, due to $v_{R}(x)=x$, is equal to his utility $u_{R}{ }^{11}$

We briefly provide a motivation of the main assumptions of the model which is supposed to capture trade in decentralized funding markets, specifically the trade of asset backed securities.

\footnotetext{
${ }^{10}$ This assumption ensures that the parties have an incentive to trade and is fulfilled, for instance, if the seller needs to raise cash and the buyer wants to store cash by investing in the asset.

${ }^{11}$ Hence, the responder's gains from trade coincide with the monetary profit subject to taxation. By ignoring a tax on the proposer's profit we can isolate the effect of taxation on the responder's incentives to produce information.
} 
(i) There are gains from trade, as liquidity management is the main purpose of trade in funding markets. (ii) Both traders have symmetric information ex ante. Before the financial crisis, asymmetric information was not considered as an issue among participants in funding markets (Deutsche Bank 2012, McKinsey 2013). Dang, Gorton and Holmstrom (2012a) actually argue that funding markets can only function if agents can maintain symmetric information. (iii) Some but not all traders can produce information about the payoff of the asset. We argue that large banks and hedge funds are more sophisticated and capable to produce information than regional banks and cash managers of corporations. ${ }^{12}$ (iv) For tractability, we assume that only the responder can acquire information. Section 6 discusses alternative information acquisition assumptions.

\section{EQUILIBRIUM ANALYSIS}

The analysis proceeds in two steps. First, we consider the responder's incentives to acquire information and his best reply to a given price $p$. Second, we derive the equilibrium price chosen by the proposer. We use these results to analyze the effect of profit taxation and sales taxes on the responder's incentives to acquire information and the consequences for the equilibrium price and trade in the next section.

\subsection{Incentives for information production}

Observing a price $p$ chosen by the proposer, the responder has three options. He can decide not to trade (choose his outside option), he can trade at price $p$ without information production, and he can acquire information and decide whether to trade conditional on the information received. The responder's "value of information" depends on the alternative option he considers to choose.

\footnotetext{
${ }^{12}$ For example, even though all investors have access to documents about asset backed securities (ABS), a small bank is less capable than hedge funds to produce information about the payoff of ABS because the valuation of these structured products requires special expertise and data intensive simulation models.
} 


\section{Definition 1 (Value of information)}

(i) $q *(x, p)$ is defined such that $q *(x, p)=\left\{\begin{array}{cc}1 & \text { if } u_{R}(x, p, 1) \geq u_{R}(x, p, 0) \\ 0 & \text { otherwise }\end{array}\right.$.

(ii) $V_{I}(p)$ is defined as $V_{I}(p)=E_{x}\left[u_{R}\left(x, p, q^{*}(x, p)\right)\right]-E_{x}\left[u_{R}(x, p, 1)\right]$.

(iii) $V_{I I}(p)$ is defined as $V_{I I}(p)=E_{x}\left[u_{R}\left(x, p, q^{*}(x, p)\right)\right]-E_{x}\left[u_{R}(x, p, 0)\right]$.

The function $q^{*}$ in Definition 1(i) describes the optimal decision rule according to which an informed responder trades: He chooses $q=1$ if and only if his utility from trading is larger than his utility from not trading, knowing the price and the true payoff $x$.

Second, $V_{I}$ is defined as the responder's expected utility conditional on knowing the true payoff $x$ of the asset (and deciding to trade according to $q^{*}$ ), minus his expected utility if he trades with probability one. Hence, $V_{I}$ is the responder's value of information when deciding between information acquisition and trading without information acquisition $(q=1)$. Third, $V_{I I}$ is defined as the responder's expected utility conditional on knowing the true payoff $x$ minus his expected utility if he does not trade at all. In other words, $V_{I I}$ is the responder's value of information when deciding between information acquisition and not trading at all without information acquisition $(q$ $=0) .{ }^{13}$ Observation 1 below is useful for the proof of subsequent results and therefore stated here explicitly.

\section{$\underline{\text { Observation } 1}$}

$V_{I}(p) \geq V_{I I}(p)$ if $E_{x}\left[u_{R}(x, p, 0)\right] \geq E_{x}\left[u_{R}(x, p, 1)\right]$.

An uninformed responder does not trade if $V_{I}(p)>V_{I I}(p)$. In the absence of taxation, $V_{I}(p)=V_{I I}(p)$ if $p=E(x)$ : Since $v_{R}(x)=x$, an uninformed responder is indifferent between trading and not trading if the price is equal to the expected payoff of the asset.

\footnotetext{
${ }^{13}$ Dang, Gorton and Holmstrom (2012a,b) introduce the terminology "information sensitivity" for the value of information in a setting without taxation.
} 
Figure 1: Value of information $V_{I}$ and $V_{I I}$ if (a) the buyer or (b) the seller is the responder.

(a) Buyer is responder

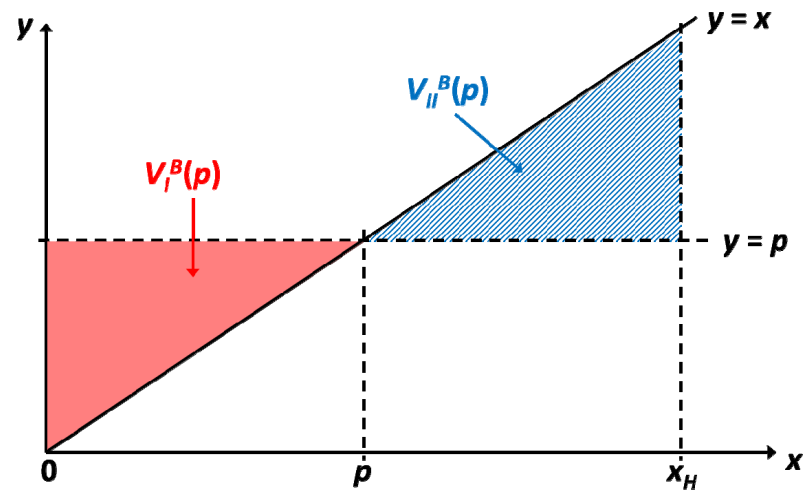

(b) Seller is responder

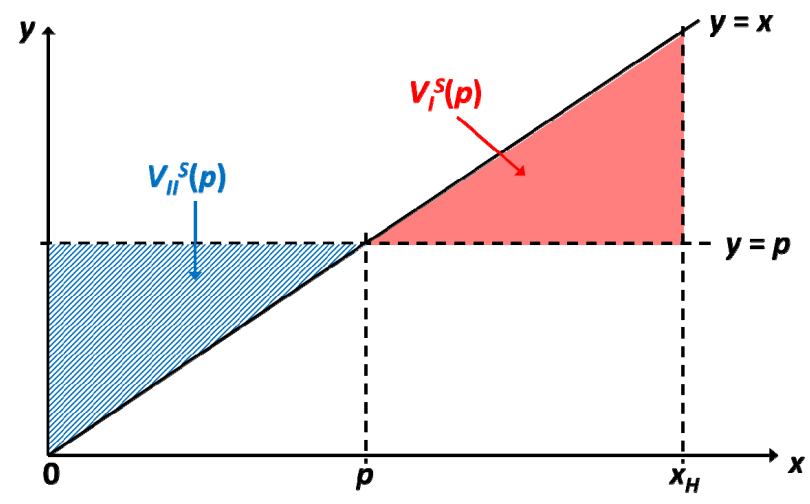

Note: $v_{R}(x)=x$; example for $x_{L}=0, \tau=0, \kappa=0$.

Figure 1 illustrates the value of information $V_{I}$ and $V_{I I}$, depending on whether the buyer or the seller is the responder and decides about information production. Consider first the buyer's incentives for information production in the left panel of Figure 1. If the buyer trades at price $p$ without having acquired information, his expected utility is equal to the area below the curve $y=$ $x$ (the expected payoff of the asset) minus the area below the curve $y=p$ (the price); hence, the expected utility when buying with probability one is equal to $V_{I I}^{B}(p)-V_{I}^{B}(p)$, weighted by the probability distribution $F(x)$. An informed buyer, however, trades if and only if the asset's true payoff $x$ is larger than the price $p$. (Recall that $v_{R}(x)=x$.) Hence, the buyer's expected utility $u_{B}$ when acquiring information and trading according to $q^{*}$ is equal to the upper triangle $V_{I I}^{B}(p)$. The payoff difference between these two options (acquiring information and trading uninformed) is defined as the value of information $V_{I}$ and is equal to the highlighted triangle below the curve $y=$ $p$ (Figure 1(a)). Moreover, since the buyer's utility is zero when he does not trade, the value of information $V_{I I}$ (when deciding between acquiring information and not trading) is equal to the highlighted triangle above the curve $y=p$.

Intuitively, when deciding between acquiring information and trading uninformed, the buyer gains from having acquired information if and only if the true return of the asset is low. Hence, the value of information $V_{I}$ measures the expected loss in low payoff states, which the buyer can avoid if he acquires information. In contrast, compared to the outside option of not trading, $V_{I I}$ 
measures the expected gain in high payoff states which the buyer gets if he acquires information and participates.

The seller's incentives to acquire information are exactly the opposite, as shown in Figure 1(b). If the seller trades with probability one, he obtains the price $p$. His value of information $V_{I}$ is equal to the expected gain in high payoff states, which the seller realizes if he acquires information and learns that the payoff of the asset is high (in which case he does not sell). Therefore, $V_{I}^{S}(p)$ is represented by the highlighted triangle above the line at $p$. Moreover, the seller's outside option of not trading is equal to the expected payoff of the asset (the area below the curve $y=x$.) Compared to this option, if the seller acquires information, he will sell the asset if the payoff $x$ is

below the price $p$ and realizes an expected gain equal to the highlighted triangle $V_{I I} S(p)$ below the curve $y=p$.

To summarize, compared to the option of trading uninformed, the buyer would like to acquire information in order to avoid a loss when buying the asset at a too high price, while the seller would like to acquire information in order to avoid to have sold the asset at a too low price. In contrast, compared to the option of not participating, the buyer's value of information is the gain from buying in high payoff states, while the seller's value of information is the gain from selling in low payoff states at a higher price.

Before we solve for the responder's best reply given a price $p$, the following lemma summarizes comparative statics results on the incentives for information production. Recall that the buyer has to pay a sales tax $\kappa \geq 0$, and hence the buyer's utility when buying depends on the tax-inclusive price $p+\kappa$ (compare the definition of $u_{B}(x, p, q)$ above), while the seller's utility depends on the net-of-tax price $p$.

\section{Lemma 1 (Comparative statics of $V_{I}$ )}

(i) Suppose that $p+\kappa>x_{L}$. If the buyer is the responder, then $V_{I}$ is (a) strictly increasing in the price $p,(\mathrm{~b})$ independent of the profit tax $\tau$, and (c) strictly increasing in the sales tax $\kappa$.

(ii) Suppose that $p<x_{H}$. If the seller is the responder, then $V_{I}$ is (a) strictly decreasing in the price $p$, (b) strictly decreasing in the profit tax $\tau$, and (c) independent of the sales tax $\kappa$.

\section{Proof: See Appendix.}


The comparative statics results for price $p$ and sales tax $\kappa$ on $V_{I}$ can be highlighted with Figure 1 above. The buyer cares about the tax-inclusive price $p+\kappa$; the higher this price, the larger becomes the highlighted triangle below the $y=p$ curve (where, in Figure 1(a), $p$ has to be replaced by $p+\kappa)$. The higher the tax-inclusive price $p+\kappa$, the higher is the probability that the true payoff of the asset is below $p+\kappa$; consequently, it becomes more valuable for the buyer to acquire information, compared to the option of trading uninformed. On the other hand, the highlighted triangle above the $y=p$ curve becomes smaller when $p$ is increased; thus, in Figure 1(b), the seller's value of information $V_{I}$ is reduced when the net-of-tax price $p$ that the seller receives is increased: A higher price $p$ makes it more attractive for the seller to sell without information acquisition. Since the buyer pays the sales tax (by assumption), the seller's value of information $V_{I}$ is independent of $\kappa$.

The effect of the profit tax is illustrated in Figure 2. Since, for the case where the buyer is the responder, $V_{I}$ corresponds to the expected loss when buying in low payoff states, a tax on positive profits has no impact on the avoidance of a potential loss and hence does not affect the value of information $V_{I}$ (the highlighted triangle below $y=p$ in Figure 2(a)). ${ }^{14}$ For the seller, however, it becomes less valuable to find out about a high payoff state and keep the asset if the payoff is subject to taxation; the highlighted triangle above $y=p$ in Figure 2(b) becomes smaller the larger $\tau$.

\section{Lemma 2 (Comparative statics of $V_{\underline{I I}}$ )}

(i) Suppose that $p+\kappa<x_{H}$. If the buyer is the responder, then $V_{I I}$ is (a) strictly decreasing in the price $p$, (b) strictly decreasing the profit tax $\tau$, and (c) strictly decreasing in the sales tax $\kappa$.

(ii) If the seller is the responder, then $V_{I I}$ is (a) strictly increasing in the price $p$, (b) decreasing in the profit tax $\tau$ (strictly decreasing if and only if $p_{0}<p$ ), and (c) independent of the sales tax $\kappa$.

Proof: See Appendix.

\footnotetext{
${ }^{14}$ We will discuss the effect of a loss offset on our main results in Section 6.
} 
Figure 2: Effect of the profit tax $\tau$ on the value of information $V_{I}$ and $V_{I I}$.

(a) Buyer is responder

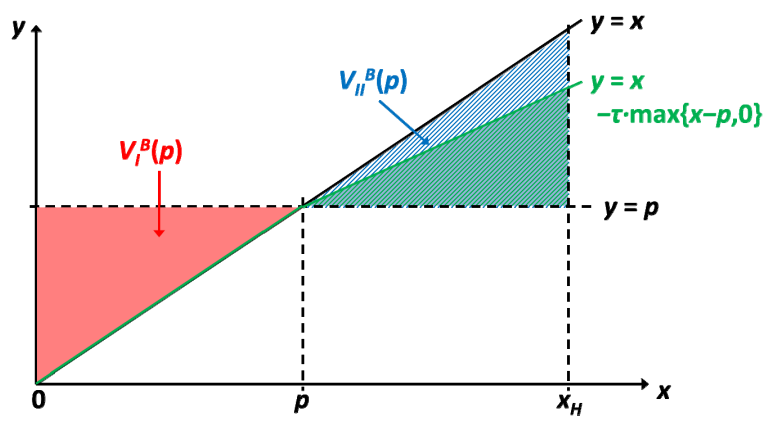

(b) Seller is responder

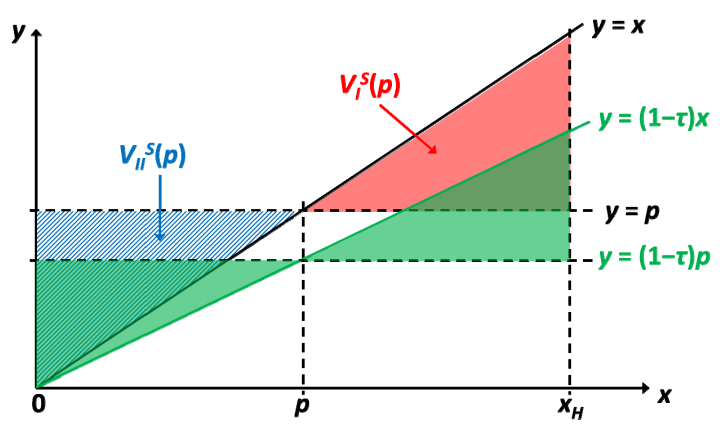

Note: $v_{R}(x)=x$; example for $x_{L}=0, \kappa=0, p_{0}=0$.

The comparative statics results for the value of information $V_{I I}$ are basically just the opposite of the previous case. Recall that $V_{I I}$ measures the utility of the responder when acquiring information and trading according to $q^{*}$ minus the utility of no trade. For the buyer, $V_{I I}$ is equal to his expected utility when acquiring information. A higher the tax-inclusive price $p+\kappa$ reduces the buyer's value of information $V_{I I}$ because an informed buyer then buys with lower probability and at a higher cost. In addition, an increase of a profit tax strictly reduces the buyer's information rent $V_{I I}$, as illustrated in Figure 2(a).

For the seller, $V_{I I}$ represents his gain from selling the asset in low payoff states (where $x<p$ ). This gain is higher the higher the price $p$ that the seller receives, but it is reduced if the profit tax is increased, as the information rent (the difference between $p$ and $x$ ) is subject to taxation. The latter effect is illustrated in Figure 2(b). Again, since the buyer pays the sales tax, $V_{I I}$ of the seller is independent of $\kappa$.

\subsection{The optimal choice of the responder}

The properties of $V_{I}$ and $V_{I I}$ can be used to determine the best reply of the responder. Facing a price $p$, the optimal decisions on information production and trading can directly be characterized as a function of the information cost $\gamma$. We assume that (a) if the responder is indifferent between trading and not trading, he decides to trade and (b) if the responder is indifferent between information acquisition and no information acquisition, he does not acquire information. 


\section{Lemma 3 (Best response of responder)}

Let $(p, \tau, \kappa)$ be given.

(i) If $V_{I} \leq \min \left\{\gamma, V_{I I}\right\}$, then the responder trades without information acquisition.

(ii) If $\gamma<V_{I}$ and $\gamma \leq V_{I I}$, then the responder acquires information and trades according to $q^{*}(x, p)$.

(iii) If $V_{I I}<\min \left\{\gamma, V_{I}\right\}$, then the responder does not acquire information and does not trade.

\section{$\underline{\text { Proof: }}$}

Part (i): Since $V_{I} \leq V_{I I}$, the responder prefers to trade uninformed over no trade (Observation 1). Moreover, $V_{I} \leq \gamma$ implies that the responder prefers to trade uninformed over information acquisition.

Part (ii): With $V_{I}>\gamma$, the responder prefers information acquisition over trading uninformed. Moreover, the responder's expected gain from information acquisition compared to his outside option is $V_{I I}-\gamma \geq 0$; hence, he can cover the information cost.

Part (iii): Since $V_{I I}<V_{I}$, an uninformed responder does not trade (Observation1). Moreover, since $V_{I I}<\gamma$, the gain from information acquisition is smaller than the cost, and the responder's optimal choice is his outside option (no information acquisition and no trade), irrespectively of whether $V_{I}>\gamma$ or not. //

The responder decides to acquire information if and only if both $V_{I}$ and $V_{I I}$ are larger than the cost of information $\gamma$. Otherwise, the responder does not acquire information; the comparison of $V_{I}$ and $V_{I I}$ reveals whether or not an uninformed responder prefers to trade. An uninformed responder does not trade if $V_{I}>V_{I I}$ (which, by Observation 1, is equivalent to $\left.E_{x}\left[u_{R}(x, p, 1)\right]<E_{x}\left[u_{R}(x, p, 0)\right]\right)$.

\subsection{Equilibrium price setting}

Taking into account the responder's best reply, there are three candidate equilibrium prices that the proposer may choose. 


\section{Definition 2 (Candidate equilibrium prices)}

(i) $\bar{p}$ is defined such that $E_{x}\left[u_{R}(x, \bar{p}, 1)\right]=E_{x}\left[u_{R}(x, \bar{p}, 0)\right]$.

(ii) $p_{I}$ is defined such that $V_{I}\left(p_{I}\right)=\gamma$.

(iii) $p_{I I}$ is defined as

$$
p_{I I} \in \arg \max _{p} E_{x}\left[u_{P}\left(x, p, q^{*}(x, p)\right)\right] \text { s.t. } V_{I I}\left(p_{I I}\right) \geq \gamma .
$$

The price $\bar{p}$ is defined such that the responder is exactly indifferent between trading with probability one at $\bar{p}$ and choosing his outside option $\bar{u}_{R}$ (no trade, no information acquisition). ${ }^{15}$ Moreover, $p_{I}$ is defined such that, when being offered a price $p_{I}$, the responder is indifferent between producing information and trading according to $q^{*}$ on the one hand and not producing information and trading with probability one on the other hand. ${ }^{16}$

Finally, $p_{I I}$ is the price that maximizes the proposer's expected utility in case the responder acquires information and trades according to $q^{*} .{ }^{17}$ Here, $p_{I I}$ takes into account the responder's participation constraint such that the responder's expected utility from producing information is weakly larger than his utility $\bar{u}_{R}$ from not participating $\left(V_{I I}\left(p_{I I}\right) \geq \gamma\right)$.

If the proposer's gains form trade are sufficiently small, he will not trade with an informed responder but rather choose his outside option $\bar{u}_{P}$. This is the case, for instance, if $v_{P}(x)$ is close to $v_{R}(x)$ : Then, a proposer will most likely make a loss when trading with an informed responder (who only trades if it is beneficial for him); hence, the proposer might choose not to participate. In the following, we will concentrate on situations where the proposer's incentives to trade are sufficiently strong or, in other words, $\bar{u}_{P}$ is sufficiently low. Technically, we assume

\footnotetext{
${ }^{15}$ By Definition 1(ii)-(iii), this is equivalent to $V_{I}(\bar{p})=V_{I I}(\bar{p})$.

${ }^{16}$ As shown in Lemma $1, V_{I}$ is strictly monotone in $p$ for prices between $x_{L}$ and $x_{H}$. For sufficiently low $\gamma, p_{I}$ is uniquely defined. If $\gamma$ is high and the seller is the responder, then $V_{I}(p)<\gamma$ for all $p \geq 0$, but then $p_{I}$ will never be relevant for the equilibrium characterization. To keep the definitions as simple as possible, we omit this case in Definition 2(ii).

${ }^{17}$ For arbitrary functions $F$ as well as $v_{S}$ and $v_{B}, p_{I I}$ is not necessarily unique. When considering the effects of taxation, we neglect this possibility of multiple $p_{I I}$ as optimal solutions (where all yield the same expected utility to the proposer), which could be easily ruled out by some further assumptions on $F$.
} 
that $E_{x}\left[u_{P}\left(x, p_{I I}, q^{*}\left(x, p_{I I}\right)\right)\right] \geq \bar{u}_{P}$, i.e., the proposer is willing to trade with an (endogenously) informed responder. ${ }^{18}$

\section{$\underline{\text { Proposition } 1}$}

Define $\quad \mathcal{L}$ such that $E_{x}\left[u_{P}\left(x, p_{I}, 1\right)\right]=E_{x}\left[u_{P}\left(x, p_{I I}, q^{*}\left(x, p_{I I}\right)\right)\right] \quad$ and suppose that $E_{x}\left[u_{P}\left(x, p_{I I}, q^{*}\left(x, p_{I I}\right)\right)\right] \geq \bar{u}_{P}$.

(i) If $\gamma \geq V_{I}(\bar{p})$, then $p^{*}=\bar{p}$ and the responder trades without information acquisition.

(ii) If $\mathcal{\chi} \leq \gamma<V_{I}(\bar{p})$, then $p^{*}=p_{I}$ and the responder trades without information acquisition.

(iii) If $\gamma<\chi$, then $p^{*}=p_{I I}$ and the responder acquires information and trades according to $q^{*}$.

\section{Proof:}

At $\gamma=\chi$, the proposer is indifferent between inducing the responder to trade with probability one (without information acquisition) on one hand and information acquisition and trade according to $q^{*}$ on the other hand.

Part (i): Suppose that $\gamma \geq V_{I}(\bar{p})$. With Definition 2(i) and the definitions of $V_{I}$ and $V_{I I}$, this implies that $V_{I}(\bar{p})=V_{I I}(\bar{p}) \leq \gamma$; hence, by Lemma 3(i), the responder trades without information acquisition. In fact, the responder's expected utility is the same as if he chooses not to participate; therefore, there is no other price that the proposer strictly prefers to $\bar{p}$ and where the responder still trades with probability one. Moreover, the proposer also strictly prefers $\bar{p}$ to $p_{I I}$ since, at $p_{I I}$, there is trade with lower probability and, in addition, the responder has to be compensated for the cost of information (he must still get at least what he gets when choosing not to participate). This shows part (i).

Part (ii): Note first that $E_{x}\left[u_{P}\left(x, p_{I}, 1\right)\right]$ is continuous and increasing in $\gamma$. Continuity in $\gamma$ follows from continuity of $u_{P}(x, p, 1)$ in $p$ and the definition of $p_{I}$. For monotonicity in $\gamma$, notice that $p_{I} \in \arg \max _{p} E_{x}\left[u_{P}\left(x, p_{I}, 1\right)\right]$ s.t. $V_{I}(p) \leq \gamma$ and that, at the optimal price $p_{I}$, the constraint $V_{I}(p) \leq \gamma$ must be binding. Hence, if $p_{I}$ is charged and trade occurs with probability one, then an increase in the cost of information makes the proposer strictly better off. (Intuitively, the constraint $V_{I}(p) \leq \gamma$ is relaxed.)

\footnotetext{
${ }^{18} \mathrm{We}$ assume this so as to save on notations.
} 
By part (i), at $\gamma=V_{I}(\bar{p})$ the proposer strictly prefers an offer $\bar{p}=p_{I}$ over an offer $p_{I I}$. By continuity and monotonicity of $E_{x}\left[u_{P}\left(x, p_{I}, 1\right)\right]$, there exists $\delta>0$ such that the proposer strictly prefers $p_{I}$ over $p_{I I}$ for all $\gamma \in\left(V_{I}(\bar{p})-\delta, V_{I}(\bar{p})\right]$. Finally, if $\gamma<V_{I}(\bar{p})$ and the proposer offers $\bar{p}$, then the responder will acquire information; thus, by definition of $p_{I I}$, the proposer (weakly) prefers $p_{I I}$ over $\bar{p}$. Altogether this shows part (ii).

Part (iii): First of all, if $\gamma$ approaches zero, then the proposer cannot avoid information acquisition of the responder, and therefore the proposer's optimal choice will be $p_{I I}$. (This requires, of course, that the proposer is willing to trade with an informed responder, i.e., it requires that the value of the proposer's outside option is sufficiently low such that $\left.E_{x}\left[u_{P}\left(x, p_{I I}, q^{*}\left(x, p_{I I}\right)\right)\right] \geq \bar{u}_{P}.\right)$ Second, $E_{x}\left[u_{P}\left(x, p_{I I}, q^{*}\left(x, p_{I I}\right)\right)\right]$ is (weakly) decreasing in $\gamma$ : If $p_{I I}$ is the unconstrained optimum, i.e. $V_{I I}\left(p_{I I}\right)<\gamma$, then a marginal increase in $\gamma$ does not affect $p_{I I}$ (because then the proposer's utility does not depend on $\gamma$ ). If, however, $V_{I I}\left(p_{I I}\right)=\gamma$, an increase in $\gamma$ makes the proposer worse off. (Intuitively, the proposer must leave a higher share in the surplus to the responder in order to compensate him for the higher cost of information and to ensure that the responder does not choose his outside option $\bar{u}_{R}$.) Therefore, the monotonicity properties of $E_{x}\left[u_{P}\left(x, p_{I}, 1\right)\right]$ and $E_{x}\left[u_{P}\left(x, p_{I I}, q^{*}\left(x, p_{I I}\right)\right)\right]$ imply there is a threshold $\chi$ such that the proposer offers $p_{I I}$ if and only if $\gamma<\chi$. //

Proposition 1 characterizes the equilibrium properties which hold both for the case where the buyer and where the seller makes the offer. The result on the equilibrium price $p^{*}$ is quite intuitive. If the cost of information is high, information production becomes irrelevant. In this case, the proposer offers the price $\bar{p}$ that gives the responder his outside option, i.e. no rents. Since trade occurs with probability one, this is the optimal price (Proposition 1(i)). Note, in the absence of taxation, for instance, this price would be equal to the responder's expected valuation $E\left[v_{R}(x)\right]$ of the asset.

For intermediate cost of information, the responder would react to such an "unfavorable" price by producing information and then trading only when a gain can be realized. The proposer, however, is better off by adjusting the price such that the responder has no incentives to produce information (Proposition 1(ii)). Technically, he chooses a price $p_{I}$ such that the value of 
Figure 3: Equilibrium price setting and information production.

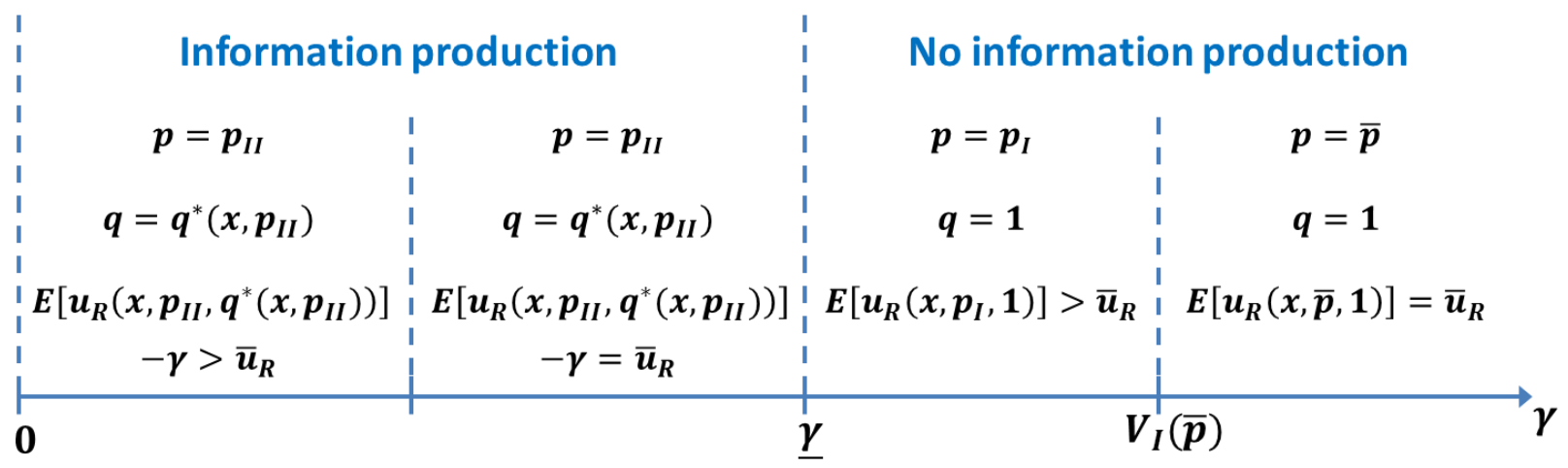

information is $V_{I}\left(p_{I}\right)=\gamma \cdot{ }^{19}$ Here, even if, in equilibrium, there is no information production, the responder gets an information rent (his equilibrium utility is higher than $\bar{u}_{R}$ ).

The lower the cost of information, the more costly it becomes for the proposer to prevent information production (the higher is the share of the surplus he has to offer to the responder). Therefore, there is a threshold $\chi$ below which the nature of the equilibrium changes and the proposer chooses a price that induces the responder to produce information (Proposition 1(iii)).

This price, however, has to take into account that the responder is being compensated for the cost of information in that his expected surplus from trade covers the cost of information production (i.e. $V_{I I} \geq \gamma$ ). While for very low cost of information this condition will always be fulfilled, it can be binding if $\gamma$ is sufficiently close to $\chi$. In the former case, the responder gets a positive net surplus $\left(V_{I I}(p)>\gamma\right)$; in the latter case, the responder's equilibrium surplus from trade net of information cost is zero $\left(V_{I I}(p)-\gamma=0\right.$, i.e., his expected utility is equal to $\left.\bar{u}_{R}\right)$. Figure 3 summarizes the results of Proposition 1, which are different from Dang, Gorton and Holmstrom $(2012 \mathrm{a}, \mathrm{b}){ }^{20}$

It is worth noting that the equilibrium payoff of the responder is not monotonic in the information cost. For low information cost, he obtains some rents in the equilibrium with information

\footnotetext{
${ }^{19}$ The buyer as a proposer will increase the price while the seller as a proposer will decrease the price so as to prevent information production by the responder.

${ }^{20}$ Dang, Gorton and Holmstrom (2012a) show that if the asset is divisible or can be used as the collateral that backs the payoff of another contract (security) then the responder does not obtain any surplus in an equilibrium with information acquisition. Dang, Gorton and Holmstrom (2012b) show that if the seller can acquire information and the uninformed buyer makes an offer, there is never information acquisition in equilibrium even if information cost is vanishingly small.
} 
acquisition. If the information cost increases, the responder's rents in the equilibrium with information acquisition are reduced to zero. If information cost is in a middle range, the responder gets rents again since he is "bribed" so as to trade without information acquisition. And if the information cost is high, the proposer is not concerned about information acquisition and the responder gets no rents as in a standard take-it-or-leave-it offer game.

\section{EFFECTS OF TAXATION ON EQUILIBRIUM PRICE AND TRADE}

The equilibrium analysis in the previous section has taxation implicitly captured in the utility functions. Using the results for the incentives to acquire information and the equilibrium price setting, we now explicitly analyze the effects of a marginal increase in the profit tax and in the sales tax, respectively, in two steps: First, we derive the effects of each of the tax instruments on the equilibrium candidate prices $\bar{p}, p_{I}$ and $p_{I I}$ (taking into account the responder's best reply). Then, we show how a tax increase affects the proposer's choice between these candidate prices and in this way affects equilibrium information acquisition.

\subsection{The effect of a profit tax}

We first consider the price effects of a profit tax increase. ${ }^{21}$

\section{Lemma 4 (Comparative statics of equilibrium prices)}

Let $\bar{p}, p_{I}$, and $p_{I I}$ be defined as in Definition 2 and consider the effect of a profit tax $\tau$.

(i) If the buyer is the responder, then (a) $\partial \bar{p} / \partial \tau<0$, (b) $\partial p_{I} / \partial \tau=0$, and (c) $\partial p_{I I} / \partial \tau \leq 0$ (with strict inequality if and only if $\left.V_{I I}\left(p_{I I}\right)=\gamma\right)$.

(ii) If the seller is the responder, then (a) $\partial \bar{p} / \partial \tau \leq 0$ (with strict inequality if and only if $p_{0}>x_{L}$ ), (b) $\partial p_{I} / \partial \tau<0$, and (c) $\partial p_{I I} / \partial \tau \geq 0$ (with strict inequality if and only if $V_{I I}\left(p_{I I}\right)=\gamma$ ).

\footnotetext{
${ }^{21}$ The results on the price effects of taxation hold for "interior prices" (between $x_{L}$ and $x_{H}$ ); otherwise, depending who is the responder, profit taxation has no effect (since no tax payment has to be made if, for instance, the buyer buys at a price above $x_{H}$ ). Moreover, as mentioned above, we assume for the following comparative statics analysis that there is a unique solution $p_{I I}$ to the proposer's maximization problem when facing an informed responder.
} 


\section{Proof:}

Part (i): Consider first the effect on $\bar{p}$. By Definition 2(i), $V_{I}(\bar{p})=V_{I I}(\bar{p})$. If the buyer is the responder, then $V_{I}$ is independent of $\tau$ (Lemma 1(i)). Since $V_{I I}$ is strictly decreasing in $\tau$ and strictly decreasing in $p$ (Lemma 2(i)), an increase in $\tau$ must be compensated by a decrease in $p$; thus, $\partial \bar{p} / \partial \tau<0$. By a similar argument, since $V_{I}$ is independent of $\tau$ and $p_{I}$ is defined such that $V_{I}\left(p_{I}\right)=\gamma$ (Definition 2(ii)), we get $\partial p_{I} / \partial \tau$ $=0$.

Now consider the effect on $p_{I I}$. Here, suppose first that the buyer's participation constraint is binding: $V_{I I}\left(p_{I I}\right)=\gamma$. Since $V_{I I}$ is strictly decreasing in $\tau$, the seller must strictly lower the price $p_{I I}$ if $\tau$ is increased; otherwise, $V_{I I}<\gamma$ and the buyer strictly prefers his outside option $\bar{u}_{B}=0$ to information acquisition (Lemma 3(iii)). If the buyer's participation constraint does not bind (that is, $V_{I I}\left(p_{I I}\right)>\gamma$ ), a marginal increase in the profit tax $\tau$ has no effect on the price $p_{I I}$; it does not affect the buyer's buying decision but simply reduces the buyer's profit that results from his informational advantage. Altogether, this shows part (i).

Part (ii): Consider first the effect on $\bar{p}$ and suppose that $p_{0} \leq x_{L}$. If the seller sells without information acquisition at price $p$, his profit is $(1-\tau)\left(p-p_{0}\right)$; if he does not sell, his expected profit is $(1-\tau)\left(E(x)-p_{0}\right)$ since there is a positive tax payment independently of the realization of $x$. Hence, $\bar{p}=E(x)$ and $\partial \bar{p} / \partial \tau=0$. Now suppose that $x_{L}<p_{0}<E(x)$ and the buyer still offers $p=E(x)$. Then, the seller's expected tax payment if he does not sell is

$$
\tau \int_{p_{0}}^{x_{H}}\left(x-p_{0}\right) d F(x)>\tau \int_{x_{L}}^{x_{H}}\left(x-p_{0}\right) d F(x)=\tau\left(E(x)-p_{0}\right)
$$

where the last term is the seller's tax payment if he sells at $p=E(x)$. Therefore, at $p=E(x)$, the seller strictly prefers to sell and the buyer can lower his offer such that $\bar{p}<E(x)$. (Intuitively, there is a "tax disadvantage" from not selling: The tax payment in case he sells at $p=E(x)$ is equal to a tax payment on a return $x$ that includes a negative tax payment in case the return $x$ turns out to be lower than $p_{0}$.) The same argument applies to the case of $E(x) \leq p_{0}<x_{H}$ where the expected tax payment is strictly positive if the seller does not sell, but is zero if the seller sells at $p=E(x)$. Since the difference in the tax payment from not selling and selling is strictly increasing in $\tau$, it holds that $\partial \bar{p} / \partial \tau<0$ if $x_{L}<p_{0}<x_{H}$.

Now turn to $p_{I}$. Since $V_{I}$ is strictly decreasing in $p$ and strictly decreasing in $\tau$ (Lemma 1 ), we have $\partial p_{I} / \partial \tau<$ 0 . Similarly, since $V_{I I}$ is strictly decreasing in $\tau$ and strictly increasing in $p$, we must have $\partial p_{I I} / \partial \tau>0$ if $V_{I I}\left(p_{I I}\right)=\gamma$ such that the seller's participation constraint binds. Otherwise, if $V_{I I}\left(p_{I I}\right)>\gamma$, then profit taxation reduces the seller's information rents but does not affect the price $p_{I I}$, just as in the case where the buyer is the responder. // 
To understand the intuition behind Lemma 4, suppose first that the cost of information is high and the proposer offers a price $\bar{p}$ such that the responder trades without information acquisition and obtains no rents, that is, expected gains and losses are equalized. If the buyer is the responder, then his gains become smaller the higher the profit tax; thus, the seller must reduce the price in order to induce the buyer to participate. If the seller is the responder and the profit tax is increased, this biases the seller's choice towards selling at price $p$ (where he pays less taxes since higher payoffs are now taxed more heavily), and the buyer can lower his offer.

For intermediate cost of information, the proposer chooses a price $p_{I}$ which just prevents information acquisition of the responder. Recall that the buyer's value of information $V_{I}$ (the value of avoiding a loss if the asset's payoff is low) is independent of $\tau$, while the seller's value of information (realizing a gain if the asset's payoff is high) is decreasing in $\tau$. Thus, if the profit tax is increased, the seller as the proposer does not have to adjust $p_{I}$, while the buyer as the proposer can lower $p_{I}$ and still prevent information acquisition of the responder.

Finally, if the cost of information is very low, then the responder acquires information and realizes a strictly positive payoff; this information rent is reduced by a profit tax increase, but the proposer's optimal price $p_{I I}$ does not change since the responder's buying decision is not affected by an increase in $\tau$. If, however, the responder's participation constraint is binding (that is, if $V_{I I}=$ $\gamma)$ and the responder's payoff is reduced by a profit tax increase, then the proposer must adjust the price $p_{I I}$ in order to compensate the responder for the higher profit tax. (The seller as the proposer must lower the price while the buyer as the proposer must increase the price.)

The most interesting case emerges for intermediate cost of information where incentives for information production have a decisive role for equilibrium price setting. As Lemma 4 shows, profit taxation can have a direct effect on the equilibrium price. Therefore, profit taxation can change the probability of trade (and thus efficiency) within an equilibrium that involves information production (where trade occurs with probability less than one). Moreover, due to the price effects, taxation of the responder's profits also affects the proposer's utility and hence his choice between the different candidate equilibrium prices (the different types of equilibria). 


\section{Proposition 2}

An increase in the profit $\operatorname{tax} \tau$

(i) increases the probability of trade in an equilibrium with information production $(\gamma<\gamma)$

(ii) and lowers the threshold $\chi$ below which there is information production in equilibrium.

\section{Proof:}

Part (i) follows directly from Lemma 4. If the buyer is the responder and the price $p_{I I}$ decreases, then the probability of trade is increased (as an informed buyer trades if and only if $x>p$ ). If the seller is the responder and the price $p_{I I}$ increases, then again the probability of trade is increased (as an informed seller trades if and only if $x<p$ ). In both cases, an increase in the profit tax strictly increases the probability of trade if and only if $V_{I I}\left(p_{I I}\right)=\gamma$.

For part (ii), recall that, at $\gamma=\mathcal{\chi}$, we have $E_{x}\left[u_{P}\left(x, p_{I}, 1\right)\right]=E_{x}\left[u_{P}\left(x, p_{I I}, q^{*}\left(x, p_{I I}\right)\right)\right]$.

Suppose first that the seller makes the offer. By Lemma 4(i), $\partial p_{I} / \partial \tau=0$ and $\partial p_{I I} / \partial \tau \leq 0$. Therefore, the seller's utility from charging $p_{I}$ is not affected by an increase in $\tau$, but his expected utility in the equilibrium candidate with information acquisition is (weakly) reduced because the price $p_{I I}$ decreases. (Since, in the equilibrium candidate with information acquisition, the seller could have charged a lower price already before the tax increase, lowering the price $p_{I I}$ must make him (weakly) worse off.) Therefore, at $\gamma=\chi$, the seller now (weakly) prefers $p_{I}$ over $p_{I I}$, which shifts the threshold $\chi$ to the left. If $\partial p_{I I} / \partial \tau=0$, then $\partial y / \partial \tau=0$, and if $\partial p_{I I} / \partial \tau<0$, then $\partial y / \partial \tau<0$.

Now suppose that the buyer makes the offer. By Lemma 4(ii), a marginal increase in $\tau$ leads to a reduction in $p_{I}$, which makes the buyer strictly better off (he still gets the asset with probability one but at a lower price). Moreover, a marginal increase in $\tau$ (weakly) increases $p_{I I}$, which makes the buyer (weakly) worse off: He gets the asset with a higher probability but pays a higher price for it. Since the buyer could have offered this higher price already before the increase in $\tau$, the price increase must reduce his profit. (Note that for prices $p$ above $p_{I I}$, an informed seller's participation constraint $E_{x}\left[u_{S}\left(x, p, q^{*}(x, p)\right)\right]-\gamma \geq \bar{u}_{S}$ is still fulfilled.) The two effects of an increase in $\tau$ on $p_{I}$ and $p_{I I}$ directly imply that, at $\gamma=\chi$, the buyer now strictly prefers $p_{I}$ over $p_{I I}$. Therefore, $\chi$ shifts to the left if $\tau$ is increased: $\partial \not / \partial \tau<0$. //

Proposition 2 identifies a direct and an indirect effect of a profit tax increase. First, in an equilibrium with information acquisition (that is, for $\gamma<\gamma$ ), profit taxation increases the probability of trade by reducing the responder's information rent, which must be compensated by 
a more favorable price for the responder. Hence, if the proposer trades with an informed responder, the price must be adjusted such that there is more trade in order to leave more rents to the responder. Second, as the indirect effect, a profit tax increase affects the proposer's choice between the equilibrium candidate prices. Since taxation of profits (weakly) reduces the incentives to acquire information (strictly for the seller), this makes it relatively more attractive for the proposer to prevent information production by offering a price $p_{I}$. Both effects lead to a higher equilibrium probability of trade. Proposition 2 holds independently of the identity of the proposer and the responder. Even though the incentive effects of taxation on information acquisition and the choice of prices are different for the buyer and the seller (Lemmas 1, 2 and 4), the effect of a profit tax on equilibrium trade works in the same direction.

While profit taxation can affect the equilibrium price when information is endogenous, a profit tax increase has no effect on the equilibrium probability of trade if asymmetric information is exogenous.

\section{Corollary 1}

Suppose that the responder is informed $(\gamma=0)$. Then, an increase in the profit tax $\tau$ does not affect the equilibrium probability of trade.

Since the case where the responder is informed can be interpreted as $\gamma=0$, the proposer's choice $p_{I I}$ is independent of $\tau .^{22}$ Hence, although it reduces the responder's information rent, a marginal increase in $\tau$ has no effect on the equilibrium probability of trade if the responder is informed. Recall that we assume that the gains from trade are large such that an uninformed proposer is willing to trade with an informed responder. So the proposer's problem is similar to a monopoly pricing problem where the proposer chooses a price $p_{I I}$ that maximizes the expected revenue, i.e., the probability of trade times the price. When $\gamma$ is small, this behavior is also present in the equilibrium with information production.

\footnotetext{
${ }^{22}$ A proof is omitted since this result follows from Lemma 3(ii) by setting $\gamma=0$ as well as from Lemma 4(i)c and (ii)c (for the case of $V_{I I}>\gamma$ ).
} 


\subsection{The effect of a sales tax}

The effects of a sales tax can be derived along similar lines. ${ }^{23}$ Consider first the effects of a marginal increase in the sales tax $\kappa$ on the equilibrium candidate prices. $^{24}$

\section{Lemma 5 (Comparative statics of equilibrium prices)}

Let $\bar{p}, p_{I}$, and $p_{I I}$ be defined as in Definition 2 and consider the effect of a sales tax $\kappa$.

(i) If the buyer is the responder, then (a) $\partial(\bar{p}+\kappa) / \partial \kappa=0$, (b) $\partial\left(p_{I}+\kappa\right) / \partial \kappa=0$, and (c) $\partial\left(p_{I I}+\kappa\right) / \partial \kappa$ $\geq 0$ (with strict inequality if and only if $V_{I I}\left(p_{I I}\right)>\gamma$ ).

(ii) If the seller is the responder, then (a) $\partial \bar{p} / \partial \kappa=0$, (b) $\partial p_{I} / \partial \kappa=0$, and (c) $\partial p_{I I} / \partial \kappa \leq 0$ (with strict inequality if and only if $\left.V_{I I}\left(p_{I I}\right)>\gamma\right)$.

Proof: See Appendix.

The comparative statics results in Lemma 5 distinguish whether the buyer or the seller is the responder. The intuition for the results, however, is the same, taking into account that the buyer as the responder bases his buying decision on the tax-inclusive price $p+\kappa$ while the seller as the responder cares about the net-of-tax price $p$. If the sales tax is increased, the relevant prices which make the responder indifferent between trading uninformed and (a) his outside option and (b) information acquisition have to remain unchanged. Hence, the seller as the proposer has to adjust his offer such that the tax-inclusive prices $\bar{p}+\kappa$ and $p_{I}+\kappa$ remain unchanged, while the buyer as the proposer has to ensure that the net-of-tax prices $\bar{p}$ and $p_{I}$ remain unchanged. The same argument holds for the price $p_{I I}$ whenever the responder's participation constraint is binding $\left(V_{I I}\left(p_{I I}\right)=\gamma\right)$.

The interesting case is a situation where $V_{I I}\left(p_{I I}\right)>\gamma$ and the responder gets a strictly positive payoff when trading at $p_{I I}$. Here, the proposer is able to shift (part of) the tax increase on to the responder by adjusting the price accordingly. This will lead to an increase in the (tax-inclusive)

\footnotetext{
${ }^{23}$ Recall that we consider a per-unit sales tax levied on the buyer. The statutory tax incidence does not affect our results; moreover, qualitatively the same results are obtained for the case of an ad valorem sales tax (for details compare the remarks in the proofs of Lemma 5 and Proposition 3).

${ }^{24} \mathrm{As}$ for the comparative statics results for the profit tax, we assume that tax-inclusive prices are in some "interior" range (between $x_{L}$ and $x_{H}$ ) and that $p_{I I}$ is unique.
} 
price if the seller makes the offer and to a decrease in the (net-of-tax) price if the buyer makes the offer.

Just as for the profit tax, a sales tax increase can have direct and indirect effects on the probability of trade, but both effects go in the opposite direction compared to the profit tax.

\section{Proposition 3}

An increase in the sales tax $\kappa$

(i) lowers the probability of trade in an equilibrium with information production $(\gamma<\chi)$

(ii) and increases the threshold $\chi$ below which there is information production in equilibrium.

\section{Proof: See Appendix.}

If the cost of information is low and there is information acquisition in equilibrium, an increase in the sales tax makes trade less attractive. Intuitively, whenever possible, the proposer shifts part of the increased tax burden to the responder, accepting that this reduces the probability of trade with an informed responder. Moreover, a sales tax increase (weakly) increases the incentives to produce information (strictly for the buyer as the responder) and therefore makes it less attractive for the proposer to offer a price that prevents information production. Finally, the tax burden is higher in the equilibrium candidate without information acquisition because there trade occurs with higher probability, which again reduces the incentives to prevent information production. Altogether, the direct and indirect effects of a sales tax increase lead to less trade and more information production.

Propositions 2 and 3 imply that the two different types of taxes can have exactly the opposite welfare effects. Profit taxation mitigates the (endogenous) lemons problem, whereas sales taxes make it worse. To be more precise, define welfare as the sum of seller's and buyer's utility and tax revenue. In this case, welfare is highest if there is trade with probability one and no information acquisition. Therefore, profit taxation can be welfare-improving, while sales taxes reduce welfare. ${ }^{25}$ This statement depends, of course, on the welfare criterion. If, for instance,

\footnotetext{
${ }^{25}$ Due to the effect on the probability of trade, this result still holds if the cost of information is not socially wasteful but only redistributive for welfare purposes.
} 
there is a negative externality of trade not captured by the seller's and buyer's utility, then a reduction of the probability of trade might be desirable, in which case the sales tax would be superior to the profit tax.

The results in Lemma 4 and Lemma 5 also allow for a direct conclusion on the tax incidence effects. Sales taxes always weakly reduce the utility both of the seller and of the buyer; whenever there is no information acquisition in equilibrium, however, the responder's utility is not affected by a sales tax increase but the proposer bears the full burden of the sales tax. In contrast, if the seller is the responder and the tax on the seller's profit is increased, this strictly increases the buyer's utility whenever the information cost is sufficiently high and either $\bar{p}$ or $p_{I}$ is offered in equilibrium. Here, taxation reduces the seller's incentives to acquire information and to choose his outside option of no trade, respectively, which enables the buyer to trade at a lower price.

\section{DISCUSSION}

In what follows we will discuss some of the assumptions made in the main analysis and their implications for our results on the effects of taxation.

\subsection{Profit taxation and deductibility of losses}

The analysis of profit taxation above only considered a tax on positive profits but did not take into account a tax treatment of losses. Sometimes, negative profits can, at least to some extent, be credited against future gains and/or other current income, and our results on the effects of taxation on the probability of trade are reinforced if the possibility of a loss offset exists.

For illustration, consider the following tax function:

$$
T_{i}(y, z)=\tau \max \{y-z, 0\}-\lambda \tau \max \{z-y, 0\}, \lambda \in[0,1] .
$$

As before, $y$ is a monetary profit and the amount $z$ is deductible for tax purposes. If $z$ is larger than $y$ (for example, because the price $p=z$ paid by the buyer is larger than the realized payoff $x$ $=y$ of the asset), then the agent receives a "subsidy" equal to $\lambda \tau \max \{z-y, 0\}$. In other words, a share $\lambda$ of the loss can be credited against other income which is also subject to the profit tax $\tau$.

Consider first the case where the buyer is the responder and can acquire information. Now, if $\lambda>$ 0 , the buyer's value of information $V_{I}$ is strictly decreasing in the profit tax $\tau$, as shown 
Figure 4: Effect of profit taxation on the value of information $V_{I}$ in case of a loss offset.

(a) Buyer is responder

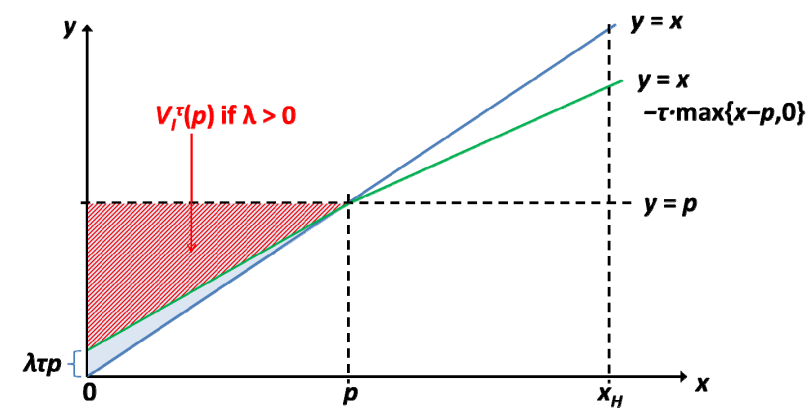

(b) Seller is responder

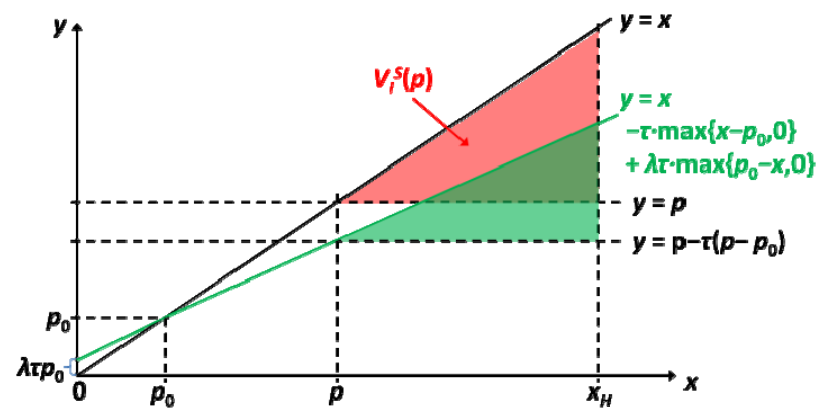

Note: $v_{R}(x)=x$; example for $x_{L}=0, \kappa=0, p_{0}<p$.

graphically in Figure 4. Recall that the buyer's value of information is equal to the value of avoiding a loss in case the payoff of the asset is low. Since this loss is lower the higher $\tau$ (the higher the "negative tax payment" in case of a loss), profit taxation reduces the buyer's value of information. Intuitively, buying the asset without information acquisition becomes less risky because the loss offset rule acts like a subsidy on the loss. It can also be interpreted as security insurance. $^{26}$

\section{$\underline{\text { Lemma } 6}$}

Suppose that $\lambda>0$ and consider the case where the buyer is the responder and can produce information. Then, $\partial p_{I} / \partial \tau>0$ and $\partial p_{I I} / \partial \tau \leq 0$ (with strict inequality if and only if the buyer's participation constraint is binding).

A proof of Lemma 6 follows the same arguments as the proof of Lemma 4 and is therefore omitted. Since $p_{I}$ is the price that makes the buyer indifferent between producing information and buying without information production and since an increase in $\tau$ strictly reduces the buyer's value of information $V_{I}$, this implies that the price $p_{I}$ is strictly increasing in $\tau$. The seller can

\footnotetext{
${ }^{26}$ Such an effect is observable in the markets for Agency mortgage backed securities (MBS). There is implicit guarantee that Agency MBS do not default. The average daily trading volume of Agency MBS in the so-called TBA (To-be-announced) markets is about $\$ 300$ billion, more than three times larger than daily stock trading at NYSE. See SIFMA (2008). This is a prime example of trade of information insensitive securities where market participants have no incentive to produce private information so that the market is very liquid.
} 
charge a higher price and still avoid information production of the buyer. On the other hand, $p_{I I}$ is decreasing in $\tau .{ }^{27}$ Therefore, if $\lambda>0$, the threshold $\chi$ below which there is information production is strictly decreasing in $\tau$ because it becomes more attractive for the seller to charge $p_{I}$ if $\tau$ is increased. Hence, as above, the profit tax has a direct positive effect on the probability of trade because it may lead to a decrease in the equilibrium price (given that $p_{I I}$ is charged) and an indirect effect because it makes it more attractive to the seller to charge a price $p=p_{I}$ that avoids information production of the buyer.

The same holds for the case where the seller is the responder and can acquire information. Here, without the possibility of a loss offset (as in the main analysis above), the seller's value of information $V_{I}$ has already been decreasing in $\tau$. This still holds if a share $\lambda$ of a negative profit can be credited against other (future) profits. Therefore, all results on the effects of profit taxation continue to hold. To sum up, the possibility of a loss offset does not qualitatively affect any of the results on the effects of taxation; in the case where the buyer can acquire information, it may even strengthen the results on the profit tax.

\subsection{Information production of the proposer}

Although in this paper we focus on the effects of taxation on equilibrium price setting and trade when the responder may be able to produce information, taxation can also affect information production and price setting when the proposer is able to produce information before making the offer. We will illustrate possible effects of profit taxation in a simplified example. For this purpose, suppose that the buyer makes the offer and that $v_{B}(x)>v_{S}(x)=x$. Moreover, suppose for simplicity that the return of the asset can be either low $\left(x_{L}\right.$, with probability $\left.\mu\right)$ or high $\left(x_{H}\right.$, with probability $1-\mu$ ). Now, the buyer decides whether to produce information before making the offer to the seller. For illustrative purposes, we assume that only the buyer is able to produce information and that he cannot credibly reveal any private information. ${ }^{28}$

If information production is unobservable to the seller and the cost of information is sufficiently low, the buyer cannot commit to not producing information and, in equilibrium, he will produce information. Then, there is an equilibrium where the buyer sets a price equal to the seller's

\footnotetext{
${ }^{27}$ The result on $p_{I I}$ is exactly as in the main analysis where $\lambda=0$. Since an informed buyer only trades if $x>p$, the possibility of a loss offset neither affects an informed buyer's utility nor his outside option $\left(V_{I I}\right.$ is independent of $\left.\lambda\right)$.

${ }_{28}^{28}$ If the buyer could credibly reveal his private information, he would prefer to do so: This would allow him to extract the entire surplus by setting a price equal to the seller's valuation $v_{S}(x)$.
} 
valuation of the asset: $p_{H}=v_{S}\left(x_{H}\right)$ if $x=x_{H}$ and $p_{L}=v_{S}\left(x_{L}\right)$ if $x=x_{L}$. The seller sells with probability one if he is being offered the high price $p_{H}$, and he sells with probability $q^{*}$ if he is being offered the low price $p_{L}$. In fact, the seller is exactly indifferent between selling and not selling; in equilibrium, $q^{*}$ will be chosen such that the buyer has no incentive to lie (that is, no incentive to offer the low price if the payoff of the asset is high). Analytically, $q^{*}$ will be such that, given that $x=x_{H}$, the buyer's after-tax profit is the same when offering $p_{H}$ and when offering $p_{L}:$

$$
v_{B}\left(x_{H}\right)-p_{H}-T_{B}\left(x_{H}, p_{H}\right)=q^{*}\left[v_{B}\left(x_{H}\right)-p_{L}-T_{B}\left(x_{H}, p_{L}\right)\right] .
$$

Now, since $v_{S}(x)=x$, the buyer does not make any monetary profit if he buys the asset from the seller at its true payoff. If, however, he lies, he does make a monetary profit which is lower the higher the profit tax $\tau$. In other words, taxation of profits reduces the buyer's incentives to lie, and therefore $q^{*}$ is strictly increasing in $\tau{ }^{29}$ Again, taxation of profits will increase the (ex ante) probability of trade.

The result that taxation may help to solve the signaling problem by reducing the incentives to lie is quite intuitive; however, a model where both parties may produce information can potentially lead to different results. In particular, for the efficiency effects of taxation it will be crucial whether information acquisition leads to asymmetric information or helps to restore a situation of symmetric information (where both parties produced the same signal). While a full analysis of such a scenario is clearly beyond the scope of this paper, we believe that it could yield further interesting results that complement the results derived in the present setting which focuses on the responder's incentives for information acquisition.

\section{CONCLUSION}

In this paper we analyze the effects of taxation on information acquisition and trade in the canonical take-it-or-leave-it offer bargaining model in which agents can realize gains from trade. We show that a profit tax and transaction (sales) tax have opposite implications for information acquisition and trade. A (marginal) increase of a profit tax can reduce the incentive to produce information and increase the probability of trade. In contrast, a (marginal) increase of a

\footnotetext{
${ }^{29}$ This result does not depend on the assumption of $v_{S}(x)=x$ (and the consequence that the buyer does not make a monetary profit when telling the truth) but holds as long as $v_{B}\left(x_{H}\right)>x_{H}>v_{S}\left(x_{L}\right)$. (If $v_{S}\left(x_{L}\right)=p_{L} \geq x_{H}, q^{*}$ is independent of $\tau$ because the tax payment is zero even if the buyer lies and offers $p_{L}$ in case $x=x_{H}$.)
} 
transaction tax can lead to more information production and lower the probability of trade. Intuitively, profit taxation makes it (relatively) less costly for the proposer to prevent information acquisition of the responder, while transaction taxes, by increasing the tax-inclusive price, make information acquisition more valuable.

By analyzing the effects of taxation on information acquisition in bilateral trade we add an important element to the bargaining and optimal contracting literature. In addition, our paper contributes to the discussion about the taxation of financial transactions in decentralized (overthe-counter) markets where bilateral bargaining is a key feature in such markets. Although the canonical take-it-or-leave-it offers bargaining model is very stylized we think that it captures important elements of bilateral trade in funding markets. Proponents of transaction taxes often refer to the disincentive effects that transaction taxes would generate for speculative trading that does not enhance market efficiency (compare European Commission, 2013, p.2). This paper, however, shows that a transaction tax can potentially lead to more speculation in decentralized trading and increase the problem of asymmetric information. ${ }^{30}$ But the taxation of profits can be efficiency enhancing when information is endogenous while it has no effect on the probability of trade when private information is exogenous.

\footnotetext{
${ }^{30}$ In the trivial case of a prohibitive high transaction tax, there will be no trade. But this is equivalent to de facto forbidding trade and active liquidity management of market participants with large cash positions in funding markets. Similarly, if the profit tax is $100 \%$, the buyer will not buy. In this paper we discuss the marginal effects of taxation and tax rates that are at basis point levels as proposed by the European Commission.
} 


\section{APPENDIX}

\section{A.1 Proof of Lemma 1}

This result follows directly from the definition of $V_{I}$. Consider first part (i). The buyer pays a profit tax if and only if he buys and the payoff of the asset is above the price paid. Hence,

$$
\begin{aligned}
V_{I}(p)=\int_{p+\kappa}^{x_{H}}(1-\tau)(x-(p+\kappa)) d F(x) \\
\quad-\left[\int_{x_{L}}^{p+\kappa}(x-(p+\kappa)) d F(x)+\int_{p+\kappa}^{x_{H}}(1-\tau)(x-(p+\kappa)) d F(x)\right] \\
=\int_{x_{L}}^{p+\kappa}((p+\kappa)-x) d F(x),
\end{aligned}
$$

which is strictly increasing in $p$ and in $\kappa$ but independent of $\tau$.

For part (ii), the seller pays a profit tax if he does not sell and the return is above the 'book value' $p_{0}$ or if he sells at price $p$ above $p_{0}$. Thus, we get

$$
\begin{aligned}
V_{I}(p) & =\int_{x_{L}}^{p}\left(p-T_{S}\left(p, p_{0}\right)\right) d F(x)+\int_{p}^{x_{H}}\left(x-T_{S}\left(x, p_{0}\right)\right) d F(x)-\int_{x_{L}}^{x_{H}}\left(p-T_{S}\left(p, p_{0}\right)\right) d F(x) \\
& =\int_{p}^{x_{H}}\left(x-p-\left(T_{S}\left(x, p_{0}\right)-T_{S}\left(p, p_{0}\right)\right)\right) d F(x),
\end{aligned}
$$

which is strictly decreasing in $p$ (as the integrand is positive and $\left.\partial T_{S}\left(p, p_{0}\right) / \partial p \leq \tau\right)$ and independent of $\kappa$ (since by definition the relevant price for the seller is the net-of-tax price $p$ ). Moreover,

$$
\begin{aligned}
\frac{\partial V_{I}}{\partial \tau}=\int_{p}^{x_{H}} & \left(\max \left\{p-p_{0}, 0\right\}-\max \left\{x-p_{0}, 0\right\}\right) d F(x) \\
& <\int_{p}^{x_{H}}\left(\max \left\{x-p_{0}, 0\right\}-\max \left\{x-p_{0}, 0\right\}\right) d F(x)=0 .
\end{aligned}
$$

Thus, $V_{I}$ is strictly decreasing in $\tau$ if the seller is the responder.

\section{A.2 Proof of Lemma 2}

Part (i) follows directly from that fact that

$$
V_{I I}(p)=\int_{p+\kappa}^{x_{H}}(1-\tau)(x-(p+\kappa)) d F(x) .
$$

For part (ii), note that

$$
V_{I I}(p)=\int_{x_{L}}^{p}\left(p-x-\left(T_{S}\left(p, p_{0}\right)-T_{S}\left(x, p_{0}\right)\right)\right) d F(x)
$$

which is independent of $\kappa$ and strictly increasing in $p$ (due to $\partial T_{S}\left(p, p_{0}\right) / \partial p \leq \tau$ ). Finally, 


$$
\begin{aligned}
\frac{\partial V_{I I}}{\partial \tau}= & \int_{x_{L}}^{p}\left(\max \left\{x-p_{0}, 0\right\}-\max \left\{p-p_{0}, 0\right\}\right) d F(x) \\
& \leq \int_{x_{L}}^{p}\left(\max \left\{x-p_{0}, 0\right\}-\max \left\{x-p_{0}, 0\right\}\right) d F(x)=0,
\end{aligned}
$$

therefore $V_{I I}$ decreases in $\tau$ (strictly if and only if $p_{0}<p$; otherwise, $V_{I I}$ is independent of $\tau$ ).

\section{A.3 Proof of Lemma 5}

Part (i): Since, by definition, the sales tax has to be paid by the buyer, the relevant price for the buyer is the tax-inclusive price $p+\kappa$. At $\bar{p}$, it holds that $E_{x}\left[u_{B}(x, \bar{p}, 1)=0\right.$. Thus, if $\kappa$ is increased, the net-of-tax price $\bar{p}$ must be lowered by exactly the same amount such that the tax-inclusive price remains unchanged: $\partial(\bar{p}+\kappa) / \partial \kappa=0$. By definition of $p_{I}$, the same arguments shows that $\partial\left(p_{I}+\kappa\right) / \partial \kappa=0$.

Regarding $p_{I I}$, recall that $V_{I I}$ is strictly decreasing in $\kappa$ (Lemma 2(i)). Therefore, if the buyer's participation constraint is binding at $p_{I I}\left(V_{I I}\left(p_{I I}\right)=\gamma\right)$ and $\kappa$ is increased, then again $p_{I I}$ must be lowered by the same amount such that $\partial\left(p_{I I}+\kappa\right) / \partial \kappa=0$. Now suppose instead that the buyer's participation constraint is not binding $\left(V_{I I}\left(p_{I I}\right)>\gamma\right)$. Then, $p_{I I}$ is the solution to the first order condition $\partial E_{x}\left[u_{S}\left(x, p, q^{*}(x, p)\right) / \partial p=0\right.$; hence, $p_{I I}$ solves

$$
\left(v_{S}\left(p_{I I}+\kappa\right)-p_{I I}\right) F^{\prime}\left(p_{I I}+\kappa\right)+1-F\left(p_{I I}+\kappa\right)=0 .
$$

With $\partial\left(p_{I I}+\kappa\right) / \partial \kappa=\partial p_{I I} / \partial \kappa+1$, total differentiation yields

$$
\begin{aligned}
\frac{\partial\left(p_{I I}+\kappa\right)}{\partial \kappa} & =-\frac{\left(v_{S}{ }^{\prime}\left(p_{I I}+\kappa\right)-1\right) F^{\prime}\left(p_{I I}+\kappa\right)+\left(v_{S}\left(p_{I I}+\kappa\right)-p_{I I}\right) F^{\prime \prime}\left(p_{I I}+\kappa\right)}{\left(v_{S}{ }^{\prime}\left(p_{I I}+\kappa\right)-2\right) F^{\prime}\left(p_{I I}+\kappa\right)+\left(v_{S}\left(p_{I I}+\kappa\right)-p_{I I}\right) F^{\prime \prime}\left(p_{I I}+\kappa\right)}+1 \\
& =-\frac{F^{\prime}\left(p_{I I}+\kappa\right)}{\partial^{2} E_{x}\left[u_{S}\left(x, p, q^{*}(x, p)\right)\right] /\left.\partial p^{2}\right|_{p=p_{I I}}}>0 .
\end{aligned}
$$

Therefore, a marginal increase in $\kappa$ strictly increases the tax-inclusive price $p_{I I}+\kappa$ if the buyer's participation constraint is not binding. ${ }^{31}$ It is worth mentioning that this result is robust to the case of an ad valorem sales tax (where the tax-inclusive price equals $(1+\kappa) p) .{ }^{32}$

\footnotetext{
${ }^{31}$ Note that, for the net-of-tax price, it is not obvious whether $\partial p_{I I} / \partial \kappa$ is positive or negative. If, for instance, $F$ is a uniform distribution and $v_{S}(x)=0$ (the seller derives no value from holding the asset), then $\partial p_{I I} / \partial \kappa=-0.5$ : The seller shifts $50 \%$ of the tax increase to the buyer and reduces the net-of-tax price by the remaining amount.

${ }^{32}$ For an ad valorem sales tax, we obtain, $\partial\left((1+\kappa) p_{I I}\right) / \partial \kappa=-v_{S}\left((1+\kappa) p_{I I}\right) F^{\prime}\left((1+\kappa) p_{I I}\right) /\left(\partial^{2} E_{x}\left[u_{S}\left(x, p, q^{*}(x, p)\right)\right] / \partial p^{2}\right)$ which is strictly positive unless $v_{S}(x)=0$. The latter case is a special case in which the optimal tax-inclusive price $z=$ $(1+\kappa) p_{I I}$ is independent of $\kappa$.
} 
Part (ii): Since the seller's decision whether to trade is based only on the net-of-tax price $p$, it follows directly that $\bar{p}$ and $p_{I}$ are independent of $\kappa$. Moreover, if for a price $p_{I I}$ the seller's participation constraint is binding such that $V_{I I}\left(p_{I I}\right)=\gamma$, then $\partial V_{I I} / \partial \kappa=0$ (Lemma 2(ii)) implies that $\partial p_{I I} / \partial \kappa=0$. (Even if the buyer wants to shift part of the tax increase to the seller by lowering his offer, this is not possible because then the seller would prefer his outside option of no trade.)

If instead $V_{I I}\left(p_{I I}\right)>\gamma$, then $p_{I I}$ solves the first order condition

$$
\frac{\partial}{\partial p} E_{x}\left[u_{B}\left(x, p, q^{*}(x, p)\right)\right]=\left(v_{B}(p)-(p+\kappa)\right) F^{\prime}(p)-F(p)=0 .
$$

Total differentiation yields

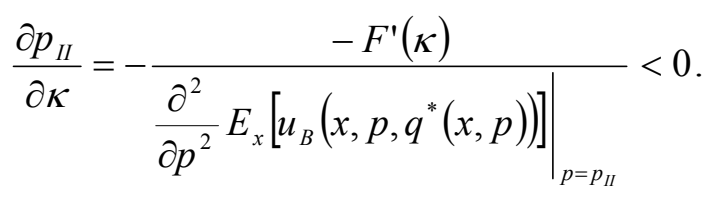

Again, this result on the sales tax does not qualitatively depend on the sales tax being a per unit tax; if instead we consider an ad valorem sales tax $\kappa$, which raises the buyer's price from $p$ to $(1+\kappa) p$, then, by total differentiating, we also obtain $\partial p_{I I} / \partial \kappa<0$ if the seller's participation constraint is not binding.

\section{A.4 Proof of Proposition 3}

Part (i): By Lemma 5(i), if the seller makes the offer, the tax-inclusive price is increasing in $\kappa$, which reduces the probability that an informed buyer buys. By Lemma 5(ii), if the buyer makes the offer, the netof-tax price is decreasing in $\kappa$, which again leads to less trade. In both cases, the probability of trade is strictly reduced if and only if the responder's participation constraint does not bind $\left(V_{I I}\left(p_{I I}\right)>\gamma\right)$.

Part (ii): Suppose first that the seller is the proposer. From Lemma 5(i), $\partial\left(p_{I}+\kappa\right) / \partial \kappa=0$ and $\partial\left(p_{I I}+\kappa\right) / \partial \kappa \geq 0$. Since $u_{S}\left(x, p_{I}, 1\right)=p_{I}$, we get

$$
\partial u_{S}\left(x, p_{I}, 1\right) / \partial \kappa=\partial p_{I} / \partial \kappa=\partial\left(p_{I}+\kappa\right) / \partial \kappa-1=-1 .
$$

Regarding the candidate price $p_{I I}$, notice that

$$
E_{x}\left[u_{S}\left(x, p_{I I}, q^{*}\left(x, p_{I I}\right)\right)\right]=\int_{x_{L}}^{p_{I I}+\kappa} v_{S}(x) d F(x)+\int_{p_{I I}+\kappa}^{x_{H}} p_{I I} d F(x) .
$$

Suppose first that $\partial\left(p_{I I}+\kappa\right) / \partial \kappa=0$. Then,

$$
\partial E_{x}\left[u_{S}\left(x, p_{I I}, q^{*}\left(x, p_{I I}\right)\right)\right] / \partial \kappa=\left(1-F\left(p_{I I}+\kappa\right)\right)\left(\partial p_{I I} / \partial \kappa\right)=-\left(1-F\left(p_{I I}+\kappa\right)\right) .
$$

Thus, the seller's profit from charging $p_{I I}$ decreases by less than his profit from charging $p_{I}$, and $\chi$ shifts to the right if $\kappa$ is increased $(\partial \chi / \partial \kappa>0)$. Now suppose that $\partial\left(p_{I I}+\kappa\right) / \partial \kappa>0$. If the equilibrium candidate price 
$p_{I I}+\kappa$ is increased following a tax increase, the seller must be strictly better off than if he had not changed the price (which would have been possible; lower prices would not violate the buyer's participation constraint). But as shown before, even if $p_{I I}+\kappa$ remained unchanged, the seller would, at $\gamma=\gamma$, strictly prefer $p_{I I}$ over $p_{I}$. Therefore, this must still hold true if the seller adjusts the price $p_{I I}$ such that $\partial\left(p_{I I}+\kappa\right) / \partial \kappa>$ 0 . Hence, again we get $\partial \not / \partial \kappa>0 .^{33}$

If the buyer is the proposer, indifference of the buyer as the proposer at $\gamma=\chi$ implies that

$$
E\left[v_{B}(x)\right]-\left(p_{I}+\kappa\right)=\int_{x_{L}}^{p_{I I}}\left(v_{B}(x)-\left(p_{I I}+\kappa\right)\right) d F(x)
$$

By Lemma 5(ii), a marginal increase in $\kappa$ has no effect on $p_{I}$ but increases the buyer's tax burden. The marginal change in the buyer's profit is -1 (which can be obtained by deriving the left hand side in the above equality with respect to $\kappa$ ). Again by Lemma 5(ii), if the seller's participation constraint is binding, a marginal increase does not have any effect on $p_{I I}$ either; however, the buyer faces a higher tax burden only with probability $F\left(p_{I I}\right)$ (in case he buys). ${ }^{34}$ Therefore, the marginal change in the buyer's profit when offering $p_{I I}$ is equal to $-F\left(p_{I I}\right)>-1$. Moreover, if the seller's participation constraint is not binding, it holds that $\partial p_{I I} / \partial \kappa<0$. The first order effect of this marginal change in the optimal price $p_{I I}$, however, is equal to zero, and again the marginal change in the buyer's profit when offering $p_{I I}$ is equal to $-F\left(p_{I I}\right)>$ -1 . (This can easily be verified by deriving the right hand side of the above equation with respect to $\kappa$, taking into account that, if $p_{I I}$ is the unconstraint maximum, we must have $\partial E_{x}\left[u_{B}\left(x, p_{I I}, q^{*}\left(x, p_{I I}\right)\right)\right] / \partial p_{I I}=0$.) Since the buyer's expected profit from offering $p_{I}$ is reduced more strongly than his expected profit from offering $p_{I I}$, the buyer now strictly prefers $p_{I I}$ over $p_{I}$ if $\gamma=\chi$. Hence, $\partial \chi / \partial \kappa>0$.

\footnotetext{
${ }^{33}$ Qualitatively the same result holds for an ad valorem sales tax: Due to the same comparative statics effects for $p_{I}$ and $p_{I I}$ as in Lemma 5 (unless $v_{S}(x)=0$ for all $x<(1+\kappa) p_{I I}$ in the case where the seller is the proposer), similar arguments as in the proof of Proposition 3 can be applied for an ad valorem sales tax.

${ }^{34}$ In case of a per unit sales tax, the change in the tax burden does not depend on the price. For an ad valorem sales tax, this is no longer true; here, however, the argument becomes even stronger: Since it holds that $p_{I I}<p_{I}$ (the buyer offers a lower price when buying from an informed seller who only sells in low payoff states), the increase in the taxinclusive price for a given increase in the ad valorem sales tax is lower if the buyer offers $p_{I I}$.
} 


\section{REFERENCES}

Acharya, Viral V., Pedersen, Lasse Heje, Philippon, Thomas, Richardson, Matthew P., 2010. Measuring Systemic Risk. FRB of Cleveland Working Paper No. 10-02.

ANDERSON, Fredrik, 1996. Income taxation and job-market signaling. Journal of Public Economics 59, 277-298.

ARnOTT, Richard, Stiglitz, Joseph E., 1986. Moral hazard and optimal commodity taxation. Journal of Public Economics 29, 1-24.

BAnerJeE, Anindya, Besley, Timothy, 1990. Moral hazard, limited liability and taxation: a principal-agent model. Oxford Economic Papers 42(1), 46-60.

BANK OF CANADA 2012. Improving the resilience of core funding markets. Working paper.

BIERBRAUER, Felix, 2012. On the incidence of a financial transaction tax in a model with fire sales. CESifo Working Paper Series No. 3870.

Cheung, Francis K., 1998. Excise taxes on a non-uniform pricing monopoly: ad valorem and unit taxes compared. Canadian Journal of Economics 31(5), 1192-1203.

CRÉMER, Jacques, KHALIL, Fahad, 1992. Gathering information before signing a contract. American Economic Review 82(3), 566-578.

CRÉMER, Jacques, KhaliL, Fahad, Rochet, Jean-Charles, 1998. Strategic information gathering before a contract is offered. Journal of Economic Theory 81(1), 163-200.

DANG, Tri Vi, 2008. Bargaining with endogenous information. Journal of Economic Theory 140, 339-354.

DAnG, Tri Vi, Gorton, Gary, HolmströM, Bengt, 2012a. The information sensitivity of a security. Working Paper.

Dang, Tri Vi, Gorton, Gary, Holmström, Bengt, 2012b. Ignorance, debt, and financial crises. Working Paper.

Deutsche BANK, 2012. Capital market bank funding. DB Research August.

Domar, Evsey D., Musgrave, Richard A., 1944. Proportional income taxation and risk-taking. Quarterly Journal of Economics 58(3), 388-422.

EUROPEAN COMMISSION, 2013. Proposal for a COUNCIL DIRECTIVE implementing enhanced cooperation in the area of financial transaction tax. (http://ec.europa.eu/taxation_customs/resources/documents/taxation/com_2013_71_en.pdf)

Fullerton, Don, Metcalf, Gilbert E., 2002. Tax incidence. Handbook of Public Economics, Volume 4, Chapter 26, 1787-1872.

Ginsburgh, Victor, Legros, Patrick, Sahuguet, Nicolas, 2010. On the incidence of commissions in auction markets. International Journal of Industrial Organization 28, 639644.

GOERKE, Laszlo, 2011. Commodity tax structure under uncertainty in a perfectly competitive market. Journal of Economics 103, 203-219.

Gorton, Gary, Metrick, Andrew, 2011. Run on Repo. Journal of Financial Economics. 
Grossman, Sanford J., Stiglitz, Joseph E., 1980. On the impossibility of informationally efficient markets. American Economic Review 70(3), 393-408.

HeRnANDO-Veciana, Ángel, 2009. Information acquisition in auctions: sealed bids vs. open bids. Games and Economic Behavior 65(2), 372-405.

IRELAND, Norman J., 1994. On limiting the market for status signals. Journal of Public Economics 53, 91-110.

IMF, 2008. Stress in bank funding markets and implications for monetary policy. in International Monetary Funds: Global Financial Stability Report, Chapter 2.

JENSEN, Sissel, SCHJELDERUP, Guttorm, 2011. Indirect taxation and tax incidence under nonlinear pricing. International Tax and Public Finance 18, 519-532.

KAPLOW, Louis, 1992. Income tax deductions for losses as insurance. American Economic Review 82(4), 1013-1017.

KeEn, Michael, 2011. The taxation and regulation of banks. IMF Working Paper 11/206.

Kotsogiannis, Christos, Serfes, Konstantinos, 2013. The comparison of ad valorem and specific taxation under uncertainty. Journal of Public Economic Theory, forthcoming.

KYLE, Albert S., 1985. Continuous auctions and insider trading. Econometrica 53(6), 1315-1335.

KYLE, Albert S., 1989. Informed speculation with imperfect competition. Review of Economic Studies 56(3), 317-355.

MATHESON, Thornton, 2011. Taxing financial transactions: issues and evidence. IMF Working Paper 11/54.

McKinsey, 2013. Between deluge and drought: The divided future of European bank funding markets. McKinsey Working Papers on Risk, No.41.

MORATH, Florian, MÜNSTER, Johannes, 2013. Information acquisition in conflicts. Economic Theory, forthcoming, DOI: 10.1007/s00199-012-0710-6.

PERSICO, Nicola, 2000. Information acquisition in auctions. Econometrica 68(1), 135-148.

SANDMO, Agnar, 1985. The effects of taxation on savings and risk taking. Handbook of Public Economics, Volume 1, Chapter 5, 265-311.

Shackelford, Douglas A., Shaviro, Daniel N., Slemrod, Joel, 2010. Taxation and the financial sector. National Tax Journal 63(4), 781-806.

SIFMA, 2008. Security Industry and Financial Market Association, Quarterly Reports.

STIGLITZ, Joseph E., 1969. The effects of income, wealth, and capital gains taxation on risktaking. Quarterly Journal of Economics 83, 263-283.

StigLITZ, Joseph E., 1989. Using tax policy to curb speculative short-term trading. Journal of Financial Services Research 3(2-3), 101-115.

SuMmers, Lawrence H., SuMmers, Victoria P., 1989. When financial markets work too well: a cautious case for a securities transactions tax. Journal of Financial Services Research 3(2-3), 261-286. 